\title{
siRNA-Lipoplex-Mediated Bcl-2 and Bcl-xL Gene Silencing Induces Apoptosis in MCF-7 Human Breast Carcinoma Cells
}

\author{
Assaf Vestin ${ }^{1}$, Elena Khazanov ${ }^{2}$, Dror Avni ${ }^{1}$, Victoria Sergeyev ${ }^{1}$, Yechezkel Barenholz ${ }^{*}, 2$, \\ Yechezkel Sidi ${ }^{*}, 1$ and Emanuel Yakobson ${ }^{1}$
}

\author{
${ }^{1}$ Laboratory of Molecular Cell Biology, Department of Medicine C, Sheba Medical Center, Tel Hashomer, 52621, and \\ Sackler School of Medicine, Tel Aviv University Ramat Aviv, 69978, Israel \\ ${ }^{2}$ Laboratory of Membrane and Liposome Research, Department of Biochemistry, Hebrew University - Hadassah Medi- \\ cal School, P.O. Box 12722, Jerusalem 91120, Israel
}

\begin{abstract}
Bcl-2 family genes play a central role in cell apoptosis and cell proliferation, and are implicated in the pathology of many malignancies. We explored different ways of introducing siRNA duplexes into cells, comparing "naked" with lipoplex- and polyplex-based formulations in order to decrease the level of the Bcl-2 and Bcl-xL proteins. Our results show that siRNA binds efficiently to all cationic liposomes used. Upon binding, siRNA reduces the zeta potential of the particles, although in most cases they remain positively charged. 70\% of MCF-7 cells took up fluorescently-labeled siRNA after $24 \mathrm{~h}$. All siRNA sequences caused growth inhibition of cells, with variable efficiency in a dose-dependent manner. Significant decreases in Bcl-2 and Bcl-xL proteins were caused by two siRNA sequences. Both caused significant growth inhibition in concentrations as low as $100 \mathrm{nM}$. These two siRNAs caused the greatest increase in caspase-7 activity and DNA fragmentation level. Addition of $\mathrm{CaCl}_{2}$ as a transfection enhancer resulted in marked increase of growth inhibition and Bcl-2 gene suppression by siRNA. Our lipoplexes containing siRNA showed equal or superior efficacy in comparison with commercial siRNA transfection kits. Efficiency of cell growth inhibition per RNA molecule using siRNA was found to be twenty fold higher than by a well-established Bcl-2 antisense oligonucleotide (ODN) molecule after optimization of ODN delivery to cells in culture. This study indicates the potential for efficient delivery of siRNA for treatment of various malignancies.
\end{abstract}

Keywords: Gene therapy, Bcl-2, Bcl-xL, siRNA, MCF-7, apoptosis, cationic lipids.

\section{INTRODUCTION}

Cancer is caused by multiple genomic aberrations that include oncogene activation, tumor suppressor inactivation, and suppression of apoptotic pathways. The regulation of apoptosis depends on the balance of pro- and anti-apoptotic proteins within the cell. In particular, the Bcl-2 homology (BH) family, encompassing both pro- and anti-apoptotic members, governs this important cell decision. Bcl-2 family genes play a central role in cell apoptosis and proliferation. Bcl-2 is an inhibitor of the mitochondrial apoptotic pathway and exerts its action by blocking the pro-apoptotic counterparts, including Bad and Bax, thereby preventing the release of cytochrome $c$ and the activation of caspase 9. Overexpression of Bcl-2 is observed in several cancers, including hematologic malignancies, as well as a range of solid tumors, including nasopharyngeal, colorectal, prostate, and breast cancers $[1,2]$. In several types of cancer, including breast cancer, it is known that there is increased expression of Bcl-2

\footnotetext{
*Address correspondence to these authors at the (YS) Laboratory of Molecular Cell Biology, Department of Medicine C, Sheba Medical Center, Tel Hashomer, 52621, and Sackler School of Medicine, Tel Aviv University Ramat Aviv, 69978, Israel; Tel: 972-3-5302464; Fax: 972-3-5302011; Email: ysidi@post.tau.ac.il, ysidi@sheba.health.gov.il and (YB) Laboratory of Membrane and Liposome Research, Department of Biochemistry, Hebrew University - Hadassah Medical School, P.O. Box 12722, Jerusalem 91120, Israel; Tel: 972-2-6758507; Fax: 972-2-6757499;

E-mail: chezyb1@gmail.com
}

and, to a lesser extent, of Bcl-xL [3-6]. However, paradoxically, Bcl-2-positive patients were reported to have a better prognosis and an overall better survival rate when compared with Bcl-2-negative patients [7, 8]. In mammary epithelial cells $\mathrm{Bcl}-2$ expression is regulated by estrogen and correlates with estrogen receptor (ER) alpha expression $[9,10]$. Thus, tumors expressing ER alpha usually express a high level of Bcl-2 and are also those that are less aggressive and less resistant to endocrine- and chemotherapy than ER-negative tumors. Therefore, cells expressing ER alpha are appropriate targets for Bcl-2 gene silencing in order to reduce the level of Bcl-2 and Bcl-xl proteins. Moreover, subsequent treatment with an estrogen antagonist such as tamoxifen may achieve a better effect after decreasing the expression of Bcl2.

Bcl-2 is capable of inhibiting cancer-chemotherapyinduced apoptosis, and overexpression of Bcl-2 confers resistance to chemotherapy $[2,3]$. One of the major limitations of cancer treatment is the marked ability of human tumors to develop and sustain resistance to chemotherapeutic drugs and radiation. The fact that defects in apoptosis can promote drug resistance downstream of the drug-target interaction strongly suggests a causal relationship between apoptosis and drug-induced cytotoxicity [11]. In this context, upregulation of the anti-apoptotic and downregulation of the proapoptotic Bcl-2 family members in tumors have been associated with their decreased susceptibility to chemo- and radio- 
therapy [2, 3]. Therefore, it has been proposed that functional blockade of either the anti-apoptotic Bcl-2 family members or overexpression of the pro-apoptotic ones could possibly change the balance of the apoptotic machinery in tumor cells and sensitize them to chemo- and radiotherapy.

It was demonstrated that chemotherapeutic drugs exert their effect in part by modulating the expression of several members of the Bcl-2 family in cancer cells. Doxorubicin causes a decrease in Bcl-2 expression and increase in Bax expression [12]. Schon and Schon have shown that imiquimod has proven clinical efficacy against basal cell carcinomas, actinic keratosis and cutaneous metastases of malignant melanoma. They found that, at least in part, this effect is mediated through interference with Bcl-2-dependent release of mitochondrial cytochrome $c$ and subsequent activation of caspase-9 [13]. The therapeutic potential of modulation of Bcl-2 and Bcl-xL gene expression has been previously explored by using antisense oligonucleotides [14]. For example, it was shown that the $\mathrm{Bcl}-2$ antisense oligonucleotide oblimersen has tumor suppressive activity and synergistic activity with chemotherapeutic agents [14, 15]. A different antisense oligonucleotide, which simultaneously downregulates Bcl-2 and Bcl-xL expression, induces apoptosis and inhibits growth of various tumor types in vitro and in vivo $[16,17]$.

Many research groups are now exploring the therapeutic potential of using Gene Silencing RNAi technology (GSRT), the process whereby a double-stranded RNA (dsRNA) induces the homology-dependent degradation of cognate mRNA and subsequent reduction of the intracellular concentration of a specific protein [18-21]. Good examples of such delivery systems are the complexes of nucleic acids with cationic lipids (lipoplexes) or with cationic polymers (polyplexes), which mediate transfection of DNA and of antisense oligonucleotides in vitro and in vivo [22-25].

In order to be efficacious, siRNA has to be delivered to the target cells; however, the chances for delivery of negatively charged siRNAs to cells in sufficient amounts are poor [26]. Therefore, convenient means should be developed for introducing siRNA into the desired cells in vitro and in vivo in order to achieve gene silencing. Cationic lipid-based lipoplexes and cationic polymer-based polyplexes are efficient delivery systems and are gaining increasing popularity. This is related to their availability, simplicity, reproducibility, and relatively low toxicity. Cationic lipids, which are the basis for lipoplexes, are amphiphiles possessing a positivelycharged headgroup responsible for nucleic acid binding (complex formation) and for complex association to the cell, followed by cell uptake; in addition it has a linker, and a hydrophobic (nonpolar) part. More than 100 cationic lipids have been developed so far, most for in vitro use, and a few for in vivo use [26-30]. Many studies have shown that lipoplexes significantly improve the intracellular delivery of oligonucleotides [22, 23, 27-31].

Polyplexes are based on a variety of water-soluble cationic polymers chemically and physically very different from the cationic lipids [31]. Lipoplexes and polyplexes share similar properties of binding nucleic acids and introducing them to cells. So far, lipoplexes are more extensively used for delivery of nucleic acids than polyplexes.
In this work, we have taken advantage of the discovery of RNAi and gene silencing as an efficient way of reduction of gene expression. Therefore, we focused on screening for Bcl-2 siRNA delivery systems, especially cationic lipids, working out conditions for optimal in vitro transfection of synthetic siRNA duplexes using a number of our cationic lipid formulations and commercial cationic liposome transfection kits, as well as one polyplex system. We performed partial physicochemical characterization of the complexes and examined their effects on growth, apoptosis, and Bcl-2 and Bcl-xL protein expression, comparing different siRNA sequences. Special interest is given to silencing of the Bcl-2 family of anti-apoptotic proteins.

\section{MATERIALS AND METHODOLOGY}

\subsection{Lipids}

Cholesterol was purchased from Sigma. The monocationic lipid 1,2-dioleyloxy-3-(trimethylamino) propane (DOTAP) and neutral lipid dioleoylphosphatidyl ethanolamine (DOPE) were obtained from Avanti Polar Lipids (Alabaster, AL). DOTAP is a monocationic glycerolipid having a quaternary amine as a single $\mathrm{pH}$-independent positive charge group (i.e., it is protonated at all pHs). Therefore, when interacting with nucleic acids, DOTAP N/P ratio (vide infra point 2.5 ) is equal to the $\mathrm{N}^{+} / \mathrm{P}^{-}$ratio. D-erythro- $N$-palmitoylsphingosyl-carbamoyl spermine (ceramide carbamoyl spermine (CCS)), a polycationic sphingolipid having 3 positive charges, composed of a mixture of D-erythro- $N$-palmitoylsphingosyl-1-carbamoyl spermine and D-erythro- $N$ palmitoyl-sphingosyl-3-carbamoyl spermine (at 4:1 mole ratio), was a gift of Dr. E. Rochlin of Bio-Lab Ltd., Jerusalem, Israel. CCS has one primary (pKa 10) and two secondary amines (pKa 8.9 and 8.0). As obvious from these $\mathrm{pKa}$ values, the degree of protonation is $\mathrm{pH}$-dependent. In the case of liposomes and lipoplexes, these groups are located in the lipid/water interface and therefore degree of ionization is affected by the surface $\mathrm{pH}$, which is high $(\mathrm{pH} 11)$ for the CCS-based liposomes when bulk (solution) $\mathrm{pH}$ is 7.4 [31]. Therefore, for the CCS-based liposomes the actual degree of protonation is not known, therefore, we used the N/P ratio (as used for polyplexes [25]) and not $\mathrm{N}^{+} / \mathrm{P}^{-}$ratio.

All lipids were at least $97 \%$ pure when analyzed by TLC. tert-Butanol was purchased from BDH, Poole, UK. Water was purified using WaterPro PS HPLC/Ultrafilter Hybrid model (Labconco, Kansas City, MO), providing sterile, pyrogen-free, highly pure water with low levels of total organic carbon and inorganic ions (18.2 megaohms), which is referred to here as "pure water". Linear polyethyleneimine (PEI) with molecular weight of 25,000 Da was obtained from Polysciences, Inc. (Warrington, PA).

\section{2. siRNA Sequences}

The E3 siRNA sequence was used by Cioca et al. to silence the Bcl-2 gene in the human myeloid leukemia cell line [32]. El and E4 siRNA sequences were previously employed to silence the Bcl-2 gene, and the E5 siRNA sequence was used to silence the Bcl-xL gene in the colorectal carcinoma cell line [29]. EJ2 and EJ5 sequences were chosen using standard rules for siRNA design [33]. The scrambled siRNA sequence has no homology whatsoever to any human gene, according to blast alignment. 


\section{Bcl-2 Sense Sequences}

E1 5' G CUG CAC CUG ACG CCC UUC 3'

E3 5' GUA CAU CCA UUA UAA GCU G 3'

E4 5' GGG GCU ACG AGU GGG AUG C 3'

EJ2 5' GUG AGG UGU CAU GGA UUAA 3'

\section{Bcl-xL Sense Sequences}

E5 5' CAG GGA CAG CAU AUC AGA G 3'

EJ5 5' GGA GAC UAG AUU GCC UUUG 3'

\section{Scrambled Sense Sequence}

\section{Scr 5' ACU CUA GCG GCA CCA UCG UGC C 3'}

All siRNA molecules were purchased from Dharmacon (Lafayette, CO). The 18 mer G3139 Bcl-2 ODN antisense was obtained forum Genta (Lexington, MA).

\subsection{Cellular Uptake of Fluorescently-Labeled siRNA}

Fluorescein-labeled siRNA was used in order to determine the percent of cells that took up siRNA. Prior to the cell uptake experiments, the siRNA was labeled with 5 ' carboxy-fluorescein (FAM) using Silencer ${ }^{\circledR}$ siRNA Labeling Kit (Ambion, Austin, TX) according to the manufacturer's instructions. In this process, 5' carboxy-fluorescein (FAM) was conjugated to the siRNA sequences in a way that does not interfere with the silencing activity of the molecule. MCF-7 cells were incubated with $400 \mathrm{nM}$ E1 siRNA, or 400 nM scrambled siRNA, or treated with lipid carrier only. Twenty four hours later, cells were fixed with paraformaldehyde solution (3\% paraformaldehyde and $2 \%$ sucrose in PBS) and stained with $1.5 \mu \mathrm{g} / \mathrm{mL}$ DAPI (4, 6 diamidino-2phenylindole) in mounting medium from Vector Laboratories, (Burlingame, CA). Cells were viewed under a fluorescent microscope, photographed and analyzed for percent of fluorescently labeled cells.

\subsection{Characterization of Cationic Lipids and PEI}

All cationic and helper lipids were analyzed for purity and quantified by TLC as described by Simberg et al. [34]. CCS and PEI were quantified based on elemental analysis. CCS was also quantified by its primary amino group using the TNBS assay [35]. In the case of CCS, both methods, nitrogen quantification and primary amines, were in good agreement.

\subsection{Preparation and Characterization of siRNA Cationic Liposome Complexes (siRNA Lipoplexes) for Transfec- tion Experiments}

Preparation of lipoplexes: Lipoplexes were formed upon mixing of cationic liposomes and nucleic acids. The lipoplexes are defined by the specific cationic lipid used and by their specific +/- charge ratio. DOTAP is a monocationic lipid, while CCS has 3 positive charges per molecule. The mole ratio of 2:1 between the cationic and neutral lipid was used for the preparation of the lipoplexes. The phosphates $\left(\mathrm{P}^{-}\right)$of the nucleic acids are the source of their negative charge. A $20 \mu \mathrm{M}$ stock solution of siRNA, which is equivalent to $820 \mu \mathrm{M} \mathrm{P}^{-}$, was diluted 10 -fold in $5 \%$ dextrose (final concentration: $82 \mu \mathrm{M}$ siRNA $\left.\mathrm{P}^{-}\right)$. Stock solutions of lipids used for the lipoplex preparations were dissolved in tertbutanol and lyophilized. Lyophilized cationic lipids were hydrated with $5 \%$ dextrose in pure water to a final concentration of $164 \mu \mathrm{M}$, which results in formation of unsized heterolamellar vesicles (UHV) [36]. For downsizing, liposomes in $20 \mathrm{mM}$ Hepes buffer, $\mathrm{pH}$ 7.4, were sonicated in an Elma transsonic $460 / \mathrm{H}$ bath sonicator for $10 \mathrm{~s}$ to obtain mostly large unilamellar vesicles (LUV). The siRNA solution was added dropwise until the desired charge ratios and concentrations were reached. The mixture was incubated for $10 \mathrm{~min}$. In the experiments an siRNA $\mathrm{P}^{-}$concentration of $41 \mu \mathrm{M}$ and a cationic lipid concentration of $82 \mu \mathrm{M}$ were used. A lipid $\mathrm{N}$ to siRNA P (N/P) ratio of 2 was used for the preparation of DOTAP-based lipoplexes and of 6, for CCS-based lipoplexes. Lipoplexes were formed at least $15 \mathrm{~min}$ before use. When precipitation occurred, the milky suspension was sonicated for a maximum of $2 \mathrm{~min}$.

In the preparation of the lipoplexes containing $\mathrm{CaCl}_{2}$, first, $\mathrm{CaCl}_{2}$ at a concentration of $25 \mathrm{mM}$ was added to the siRNA solution and incubated for $10 \mathrm{~min}$, then siRNA solution was added dropwise to the LUV until the desired charge ratios and concentrations were reached.

In the preparation of the cationic polymer PEI complexes with siRNA, a stock solution of PEI $(7.5 \mathrm{mM}$ of nitrogen, which is $21 \%$ by elemental analysis) was prepared in Hepes buffer $(20 \mathrm{mM}, \mathrm{pH} 7.4)$. Mixing of cationic polymers and nucleic acids resulted in formation of polyplexes. The polyplexes are defined by the ratio of positive charges expressed as number of nitrogen atoms $(\mathrm{N})$ to number of nucleic acid phosphate $(\mathrm{P})$ groups to give a N/P ratio. The siRNA was added to PEI at N/P ratio of 45 and incubated for $10 \mathrm{~min}$.

Determination of zeta potential: Zeta potential was measured at $25{ }^{\circ} \mathrm{C}$ using a Zetasizer Nano-Z, Malvern Instruments Ltd, Malvern, UK. An aliquot of $100 \mu \mathrm{L}$ of liposomes or lipoplexes was diluted in $600 \mu \mathrm{L}$ of $20 \mathrm{mM}$ Hepes ( $\mathrm{pH}$ 7.4). The principle of zeta potential measurement and equation for calculation are described elsewhere [37].

Determination of level of siRNA binding to cationic liposomes by ethidium bromide (EtBr) intercalation exclusion assay: Liposomes made of $16.4 \mathrm{nmol}$ of cationic lipid were mixed with $8.2 \mathrm{nmol}$ of siRNA in order to achieve an siRNA $\mathrm{P}^{-}$/cationic lipid mole ratio of $1 / 2$. After $10 \mathrm{~min}$ of incubation at room temperature, $2.5 \mathrm{nmol}$ of $\mathrm{EtBr}$ was added to each sample, followed by an additional $10 \mathrm{~min}$ of incubation [38]. EtBr fluorescence intensity was measured using an excitation wavelength of $260 \mathrm{~nm}$ and emission wavelength of $591 \mathrm{~nm}$ by LS50B luminescence spectrometer (Perkin Elmer, Norwalk, CT). The fluorescence intensity was expressed as the percentage of maximum fluorescence signal obtained for the same concentration $(8.2 \mathrm{nmol})$ of free siRNA.

Size distribution measurements: Mass-weighted size distribution of the liposomes and complexes was determined at $25{ }^{\circ} \mathrm{C}$ by dynamic light-scattering (DLS) using the ALVNIBS/HPPS particle sizer ALV-Laser Vertriebsgesellschaft $\mathrm{GmbH}$ (Langen, Germany). This instrument allows measuring size without diluting the sample, even at the millimolar lipid concentration range, so that no dilution-induced changes occur during measurements. 


\subsection{Cell Cultures}

MCF-7 cells were grown in DMEM medium supplemented with glutamine, antibiotics and $10 \%$ fetal calf serum in an incubator at $37^{\circ} \mathrm{C}$ under $5 \% \mathrm{CO}_{2}$. All culture medium components were purchased from Biological Industries (Beit-HaEmek, Israel).

\subsection{Transfection of MCF-7 Cells}

For determination of siRNA transfection with commercial kits, transfection was performed in 24-well plates. Cells were seeded at $7.5 \times 10^{4}$ cells per well in a volume of $500 \mu \mathrm{L}$. The transfection was performed using siIMPORTER cationic lipid transfectants and the corresponding siRNA, following the manufacturer's instructions (Upstate Cell Signaling, Charlottesville, VA). All experiments were performed at 24,48 and $72 \mathrm{~h}$ post transfection.

For determination of siRNA transfection with our lipidbased carriers, MCF-7 cells were plated into 96-well plates $\left(4.0 \times 10^{3}\right.$ cells/well $)$ and incubated at $37^{\circ} \mathrm{C}$ with the specified concentrations of siRNA complexed with 2,4 and $8 \mu \mathrm{M}$ cationic lipids in parallel and incubated for 48-72 h. A solution of $5 \%$ dextrose (without lipoplexes) was added to the control wells. For transfection of MCF-7 cells with PEI, 25, 50 and $100 \mathrm{nM}$ siRNA was complexed with $0.25,1.0$ and 2.0 $\mu \mathrm{M}$ PEI in parallel and incubated for $48 \mathrm{~h}$. Hepes buffer (without polyplex) was added to the control wells.

\subsection{Determination of MCF-7 Cell Survival}

Viable cells were counted using the trypan blue or the methylene blue (MB) staining assay [39]. For determination of cell survival by the MB assay, following $24 \mathrm{~h}$ of incubation in culture, different concentrations of drugs were added to each well. After fixed time intervals of drug exposure, the drug-treated cells, as well as control cells, were washed with pure water and fixed by adding $50 \mu \mathrm{L}$ of $2.5 \%$ glutaraldehyde to each well for $15 \mathrm{~min}$. The fixed cells were rinsed 10 times with pure water and once with borate buffer $(0.1 \mathrm{M}$, $\mathrm{pH} 8.5)$, dried, and stained with $\mathrm{MB}(100 \mu \mathrm{L}$ of $1 \%$ solution in $0.1 \mathrm{M}$ borate buffer, $\mathrm{pH} 8.5$ ) for $1 \mathrm{~h}$ at room temperature. Stained cells were rinsed thoroughly with pure water to remove any non-cell-bound dye, and then dried. The MB bound to the fixed cells was extracted by incubation at $37^{\circ} \mathrm{C}$ with $200 \mu \mathrm{L}$ per well of $0.1 \mathrm{~N} \mathrm{HCl}$ for $1 \mathrm{~h}$, and the net optical density of the dye in each well was determined using an absorbance plate reader (Multiskan Bichromatic Labsystems, Finland) at $620 \mathrm{~nm}$. For determination of viable cell counts by trypan blue staining, after fixed time intervals of drug exposure, the drug-treated cells, as well as control cells, were washed and the incubation continued in fresh medium until termination of the experiment. At the end of the experiment, cells were trypsinized, centrifuged, stained with trypan blue and counted using a hemocytometer.

\subsection{Assessment of Apoptosis}

Apoptosis assays were performed in 96-well plates. The caspase-7 activity was checked in MCF-7 cells by Apo-ONE Homogenous Caspase-3/7 assay (Promega, Madison, WI) according to manufacturer's instructions. This assay uses Rhodamine-110 conjugated to the amino acid sequence DEVD, a target sequence of caspases-3 and -7, which emits fluorescence upon cleavage. MCF-7 cells have a non-active truncated caspase- 3 due to a deletion mutation of 47 bases in exon 3 of the caspase- 3 gene [40]. Therefore, the activity measured in this test is that of caspase-7. Briefly, MCF-7 cells $\left(4.0 \times 10^{3}\right.$ cells/well $)$ were treated for $24 \mathrm{~h}$ with various siRNA lipoplex formulations. The caspase-3/7 reagent (100 $\mu \mathrm{L}$ ) was added to each well containing $100 \mu \mathrm{L}$ of blank, control or treated cells. For detection of caspase-7 activity, cells were incubated with the kit components for $6 \mathrm{~h}$, then fluorescence was measured at excitation wavelength $485 \mathrm{~nm}$ and emission wavelength $530 \mathrm{~nm}$ using the Synergy HT plate reader in fluorescence mode (Bio-Tek, Winooski, VT).

The level of DNA fragmentation was detected in treated MCF-7 cells after $48 \mathrm{~h}$ incubation "Cell Death Detection ELISA Plus" (Roche Applied Bioscience, Basel, Switzerland). The detection is quantitative and is based on the ELISA principle, using mouse monoclonal antibodies directed against DNA and histones, respectively. This allows the specific detection and quantitation of mono- and oligonucleosomes that are released into the cytoplasm of cells that die from apoptosis.

\subsection{Determination of the Bcl-2 Protein by Bcl-2 ELISA Assay}

Briefly, MCF-7 cells $\left(1.0 \times 10^{6}\right.$ cells/well $)$ were treated for 16 or $24 \mathrm{~h}$ with various siRNA lipoplexes. Cell lysates were prepared, and the level of Bcl-2 was determined in treated and untreated (control) cells. The Bcl-2 ELISA assay (Bender MedSystems Vienna, Austria) was used according to manufacturer's instructions. The absorbance at $450 \mathrm{~nm}$ was measured using the Multiscan Bichromatic.

\subsection{Determination of the Level of Bcl-2 and Bcl-xL by Western Blotting}

We used the procedure of Onuki et al. [41]. Briefly, 24 or $48 \mathrm{~h}$ post transfection, cells were washed with cold PBS, and then with lysis buffer containing sodium deoxycholate $0.5 \%$, Tris-HCI $0.01 \mathrm{M}, \mathrm{NaCl} 0.15 \mathrm{M}, \mathrm{NP}_{40} 0.5 \%$ and Protease Inhibitor Cocktail (Sigma-Aldrich). A cell scraper was used to remove cells to Eppendorf tubes, which were put on ice for $30 \mathrm{~min}$ and then centrifuged at $14.000 \mathrm{rpm}$ for $2 \mathrm{~min}$. A sample was taken for determination of protein [42]. Laemmeli buffer was added at a volume equal to the cell lysate. This was heated to $100{ }^{\circ} \mathrm{C}$ and loaded onto a $10 \%$ polyacrylamide gel. The membrane was blocked using $\mathrm{Su}-$ perBlock blocking buffer (Pierce, Rockford, IL) for $1 \mathrm{~h}$, followed by $1 \mathrm{~h}$ incubation with primary Bcl-2 or Bcl-xL antibody (1:1000, DakoCytomation, Glostrup, Denmark). After one hour of incubation with horseradish peroxidase, conjugated secondary antibody was added (1:10000, Jackson Immunoresearch, Minneapolis, MN). SuperSignal West Pico Chemiluminescent Substrate (Pierce, Rockford, IL) was used, and the membrane was exposed to X-ray film.

\subsection{Determination of the Level of Bcl-2 and Bcl-xL by RT-PCR}

Cells were seeded on a 6-well plate for $24 \mathrm{~h}$. After $24 \mathrm{~h}$, cells were transfected and incubated for another $48 \mathrm{~h}$. RNA was extracted with the Mini Isolation RNA kit (Zymo Research Corporation, Orange, CA) according to manufacture's instructions. Equal amounts of RNA (500 ng) from each treatment were subjected to the two-step RT-PCR assay. cDNAs were made using the Reverse-iT $1^{\text {st }}$ strand synthesis 
kit (Abgene, Epsom, UK). The PCR amplification was performed using the Ready mix reaction kit (dNTP, mM, buffer, Taq polymerase (Abgene) using specific primers.

\section{RT-PCR Primers Sequences}

$\underline{\text { Actin }}$

$$
\begin{aligned}
& \text { 5' CCTGGCACCCAGCACAAT 3' } \\
& \text { 5' GCCGATCCACACGGAGTACT 3' }
\end{aligned}
$$

$\underline{\mathrm{Bcl}-2}$

5'GTGAACATTTCGGTGACTTCC 3'

5' CCTTCACCATGTCCTTCTGA 3'

\section{RESULTS}

\subsection{Bcl-2 siRNA Lipoplexes: Design and Physicochemical Characterization}

The level of binding of siRNA to cationic liposomes was determined by the EtBr intercalation exclusion assay, as described in Materials and Methods. It was found that when E1 siRNA was complexed with several cationic unisized heterolamelar vesicles UHV (all lipid compositions, except that of DOTAP/Cholesterol), almost no EtBr fluorescence was observed (Table 1), indicating that all siRNA is associated with the cationic liposomes. Similar results were obtained with other siRNA sequences that were tested.

We also studied the zeta potential of cationic liposomes and lipolexes containing E1 siRNA. As expected, all DOTAP- and CCS-based liposomes showed positive zeta potential (Table 2). The DOTAP-based liposomes had a higher zeta potential than those based on CCS, as expected from the difference between the quaternary amine of DOTAP and the three amines (one primary and two secondary) of the CCS (see Scheme 1 with structural formulas and [22]). Addition of siRNA to these UHV decreased their zeta potential. We found that decrease of the zeta potential of UHV was dependent on the cationic lipid/siRNA ratio and on the type of helper lipid. Namely, at the N/P ratio of 2 for DOTAP- and 6 for CCS-based lipoplexes, the decrease was more pronounced than in lipoplexes having the N/P ratio of 5 and 15 for DOTAP- and CCS-based lipoplexes, respectively (Table 2). These results were also consistent with our results obtained from the EtBr binding assay, which showed that in DOTAP/Cholesterol lipoplexes at N/P ratio of 2, $20 \%$ of siRNA remained unbound (free) (Table 1). In parallel, these lipoplexes show a reversal from positive to negative zeta potential (Table 2). These results indicate that in almost all lipoplexes siRNA was efficiently bound to cationic lipids.

Table 1. Binding of E1 siRNA to Cationic Lipid-based Unsized Heterolamellar Vesicles (UHV).

\begin{tabular}{|l|c|}
\hline \multicolumn{1}{|c|}{ Cationic Lipoplex Formulations } & Free siRNA (\%) \\
\hline \hline CCS/siRNA & 0 \\
\hline DOTAP/siRNA & 0 \\
\hline CCS/DOPE /siRNA & 0 \\
\hline DOTAP/DOPE/siRNA & 0 \\
\hline CCS/Chol/siRNA & 0 \\
\hline DOTAP/Chol/siRNA & 20 \\
\hline
\end{tabular}

Note: N/P mole ratio of 2 or 6 was used for preparation of DOTAP- and CCS-based lipoplexes, respectively. The level of siRNA binding to cationic liposomes was measured by EtBr intercalation assay.

Size distribution analysis by DLS shows that DOTAPand CCS-based UHV were in the size range of $100-500 \mathrm{~nm}$, depending on their composition, with the size of DOTAP-based liposomes being about half of the CCS-based lipoplexes (Table 2). Addition of siRNA to these cationic UHV (regardless of their composition) to form lipoplexes, resulted in an increase in particle size. The average size of DOTAP-based lipoplexes was $~ 2$-fold that of the DOTAP-based UHV. On the other hand, addition of siRNA to

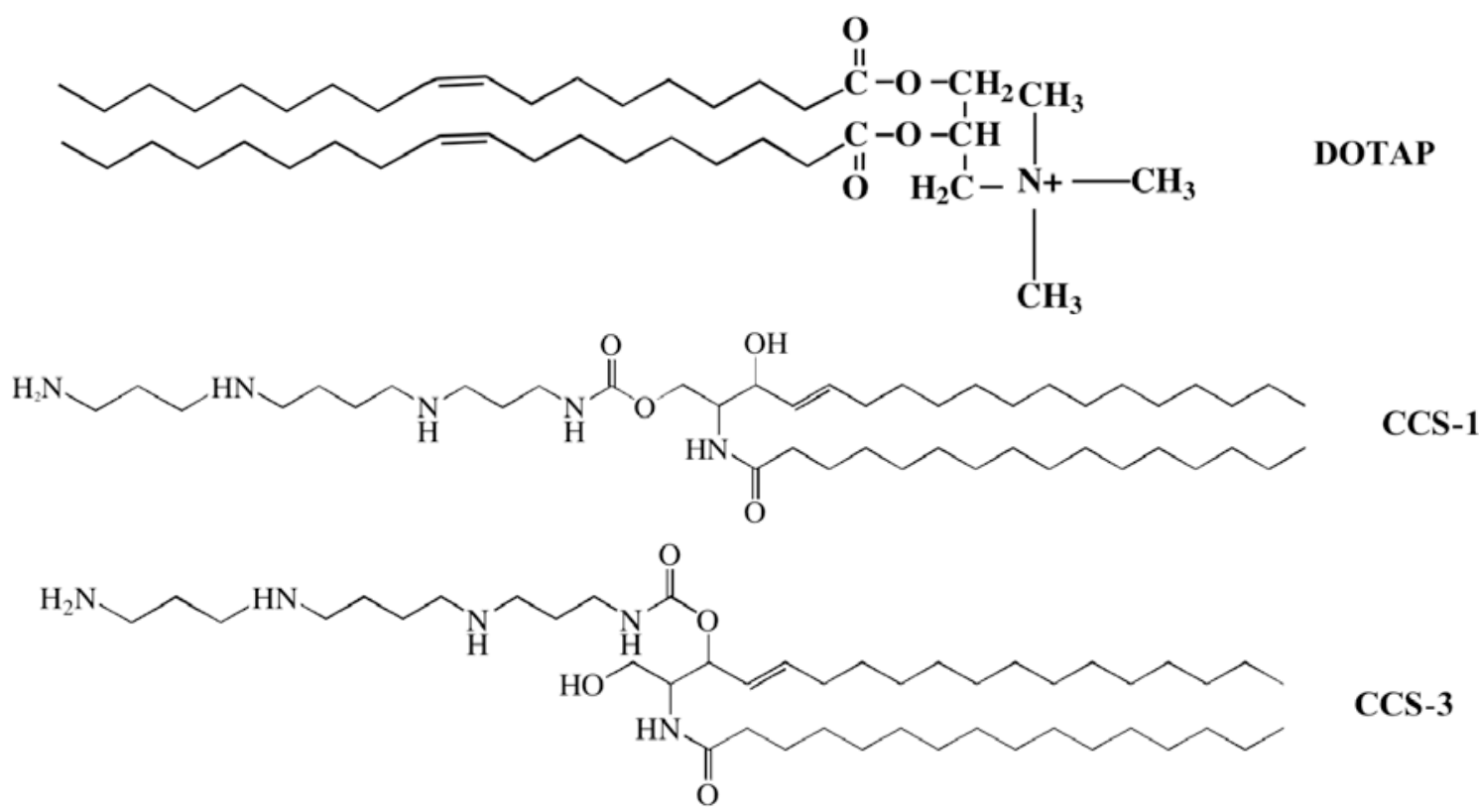

Scheme 1. Structural formulas of 1,2-dioleyloxy-3-(trimethylamino)-propane (DOTAP), D-erythro- $N$-palmitoyl-sphingosyl-1-carbamoyl spermine (CCS-1) and D-erythro- $N$-palmitoyl-sphingosyl-3-carbamoyl spermine (CCS-3). 
Table 2. Physicochemical Characteristics of Different Liposomes and Lipoplexes

\begin{tabular}{|c|c|c|c|}
\hline Formulations & Lipid $^{+} /$siRNA $^{-}$charge ratio & Size (Range), nm & Zeta Potential (mV) \\
\hline siRNA & siRNA only & - & $-39 \pm 2.0$ \\
\hline PEI & Polymer only & $73.1 \pm 23.5$ & $18.1 \pm 1.1$ \\
\hline DOTAP & Lipid only & $176 \pm 52$ & $99 \pm 3.2$ \\
\hline DOTAP/DOPE & Lipid only & $105 \pm 23$ & $82 \pm 1.0$ \\
\hline DOTAP/Chol & Lipid only & $206 \pm 28$ & $67 \pm 2.6$ \\
\hline $\mathrm{CCS}$ & Lipid only & $301 \pm 76$ & $62 \pm 1.2$ \\
\hline CCS/DOPE & Lipid only & $264 \pm 106$ & $80 \pm 1.0$ \\
\hline CCS/Chol & Lipid only & $467 \pm 48$ & $71 \pm 5$ \\
\hline DOTAP/siRNA & 2 & $356 \pm 54$ & $59 \pm 1.0$ \\
\hline DOTAP/DOPE/siRNA & 2 & $226 \pm 36$ & $60 \pm 2.0$ \\
\hline DOTAP/Chol/siRNA & 2 & $128 \pm 46$ & $-65 \pm 6.0$ \\
\hline CCS/siRNA & 6 & 2883 (broad distribution) & $40 \pm 2.0$ \\
\hline CCS/DOPE/siRNA & 6 & 3439 (broad distribution) & $59 \pm 1.0$ \\
\hline CCS/Chol/siRNA & 6 & 2078 (broad distribution) & $34 \pm 1.8$ \\
\hline DOTAP/siRNA & 5 & $338 \pm 12$ & $61 \pm 5.6$ \\
\hline DOTAP/DOPE/siRNA & 5 & $296 \pm 38$ & $63 \pm 5.5$ \\
\hline DOTAP/Chol/siRNA & 5 & $286 \pm 56$ & $71 \pm 5.0$ \\
\hline CCS/siRNA & 15 & 3568 (broad distribution) & $47 \pm 2.0$ \\
\hline CCS/DOPE/siRNA & 15 & 4236 (broad distribution) & $61 \pm 2.5$ \\
\hline CCS/Chol/siRNA & 15 & 3698 (broad distribution) & $71 \pm 3.5$ \\
\hline
\end{tabular}

Note: Mole ratio of cationic to neutral lipid of 2:1 was used for the preparation of liposomes and lipoplexes.

the CCS-based UHV caused a much larger increase in both mean particle size and in particle size heterogeneity (Table 2).

\subsection{Uptake of siRNA by MCF-7 Cells}

MCF-7 cells were incubated with $400 \mathrm{nM}$ E1 siRNA or scrambled siRNA. Cells incubated with cationic liposomes only were included in the control group. After $24 \mathrm{~h}, \mathrm{MCF}-7$ cells were viewed under a fluorescent microscope, photographed and the percent of cells that took up labeled lipoplexes was determined. Our results (Fig. 1) indicate that 60$70 \%( \pm 5 \%)$ of the MCF-7 cells took up the E1 siRNA (see green staining of the DAPI-stained nuclei). Moreover, MCF7 cells treated with lipolexes containing scrambled siRNA, but not with cationic liposomes, revealed positive staining (see green-stained nuclei in Fig. 1).

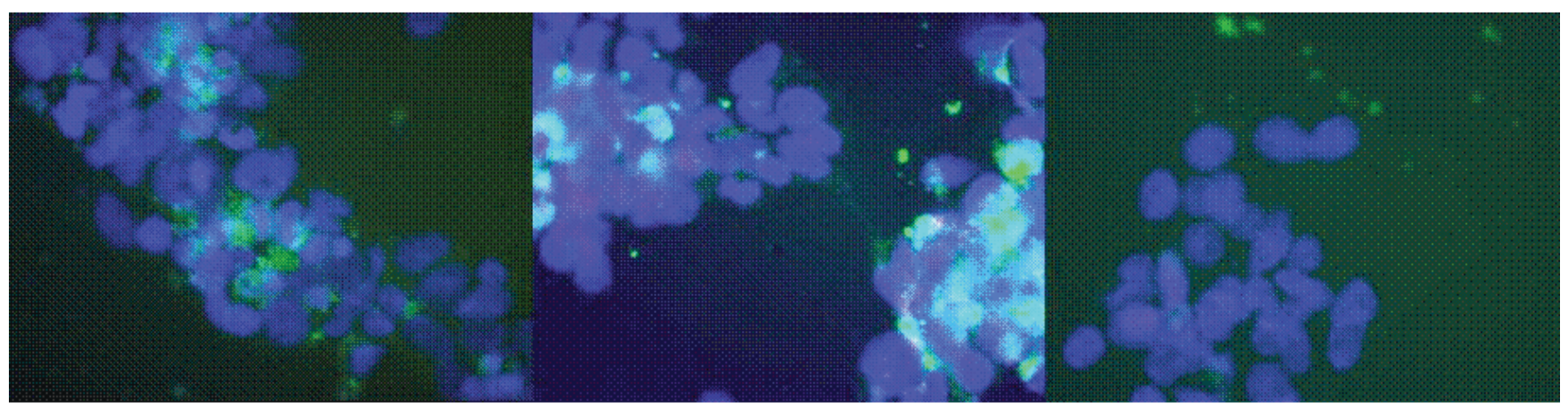

Scrambled siRNA

200nM anti Bcl-2 siRNA

Mock treated Cells

Fig. (1). Uptake of labeled E1 siRNA by MCF-7 cells. MCF-7 cells were transfected with E1 siRNA (400 nM), scrambled siRNA (400 $\mathrm{nM}$ ) or treated with the tranfection agent only (mock). Prior to the transfection the siRNA was labeled with FAM using Silencer ${ }^{\circledR}$ siRNA labeling kit. $24 \mathrm{~h}$ after transfection, cells were fixed with paraformaldehyde solution (3\% paraformaldehyde and 2\% sucrose in PBS) and stained with DAPI (mounting medium containing $1.5 \mu \mathrm{g} / \mathrm{mL}$ of DAPI). 


\subsection{Growth Inhibitory Activity of Bcl-2 and Bcl-xL siRNA - Screening Studies for Optimal siRNA Se- quences}

To assess the growth inhibitory activity of siRNA duplexes, MCF-7 cells were plated at $25 \%$ confluence, transfected, and allowed to grow for $48 \mathrm{~h}$. Microscope images of stained MCF-7 cells are presented in Figs. (2A-J). Inhibition of growth was clearly observed in cells transfected with either E1 Bcl-2 (Fig. 2E, F) or E5 Bcl-xL (Fig. 2I, J) siRNAs complexed with siIMPORTER cationic lipids. In contrast, no inhibition of growth was observed in untreated cells (Fig. $2 \mathrm{~A}, \mathrm{G})$ or in cells that were treated with the transfection reagent only (mock) (Fig. 2B, H).

Next we compared the efficacy of growth inhibition using the different siRNA sequences, E1, EJ2, E3 and E4, which target the Bcl-2 mRNA, and E5 and EJ5, which target the Bcl-xL mRNA. We also explored combining two siR$\mathrm{NAs}$, the pair E1+E3 and the pair E1+E5. The appropriate duplexes were added to MCF-7 cells in complexes with siIMPORTER cationic lipids at increasing concentrations and compared to scrambled siRNA sequences complexed with cationic lipids. Then, cells were stained with trypan blue and counted by hemocytometer. The quantification of the growth inhibitory effect of the various siRNA duplexes is depicted in Fig. (3). We observed a decline in cell number as early as $24 \mathrm{~h}$ post transfection. At $250 \mathrm{nM}$ both E1 and E5 cause a nearly $50 \%$ decrease $\left(\mathrm{IC}_{50}\right)$ in percentage cell survival (Fig. 3A). The $\mathrm{IC}_{50}$ for $\mathrm{EJ} 2, \mathrm{E} 3$ and $\mathrm{E} 4$ sequences is over $1000 \mathrm{nM}$ (Fig. 3A). There is a significant difference (Wilcoxon, $p<0.05)$ between the growth inhibition achieved by the E1 and E5 siRNAs and the other sequences. Fig. (3A) shows that E1 siRNA, which is directed against Bcl-2, has a significantly higher growth inhibitory effect on cell survival than E5 and EJ5, which are directed against Bcl-xL. The combination of E1 and E3 resulted in antagonistic interaction and inhibited MCF-7 cell growth less than each duplex alone (Fig. 3B). On the other hand, the combination of E1 and E5 was more effective than each one of the sequences; however, its effect was less than additive (Fig. 3B). The transfection agent siIMPORTER caused minimal growth inhibition, less than $10 \%$. Scrambled siRNA had no effect on growth of MCF-7 cells (Fig. 3A). For the following experiments, we chose to work with the best siRNA sequence for each target. Therefore, we continued our studies with E1 Bcl-2 and E5 Bcl-xL siRNAs.
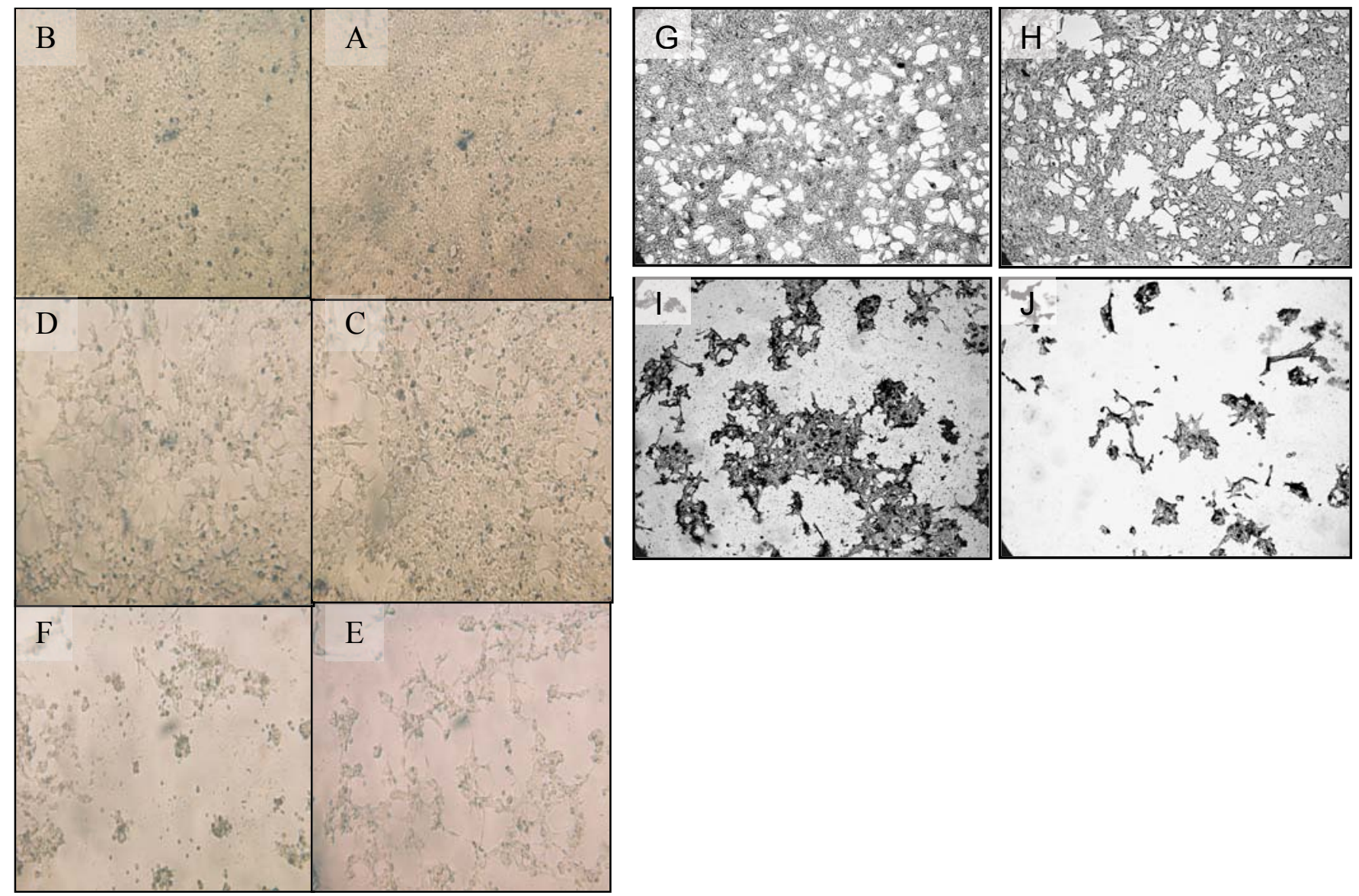

Fig. (2). In situ growth inhibitory effect of lipoplexes containing E1 Bcl-2 and E5 Bcl-xL siRNAs. MCF-7 cells were transfected with cationic lipid transfectant (siIMPORTER) containing E1 Bcl-2 and E5 Bcl-xL siRNAs. Images show MCF-7 cells treated for $48 \mathrm{~h}$ with E1 Bcl-2 siRNA (A-F) or with E5 Bcl-xL siRNA (G-J). A - Untreated cells. B - Cells treated with transfection reagent only (mock). C - 100 nM E1 treated cells. D - $250 \mathrm{nM}$ E1 treated cells. E - $500 \mathrm{nM} \mathrm{E1}$ treated cells. F - $1000 \mathrm{nM}$ E1 treated cells. $\mathbf{G}-\mathbf{U n t r e a t e d}$ cells. H - Cells treated with transfection reagent only (mock). I - $500 \mathrm{nM}$ E5 treated cells. J - $1000 \mathrm{nM}$ E5 treated cells. The cells are photographed under an inverted microscope at $\times 40$ magnification. 
A

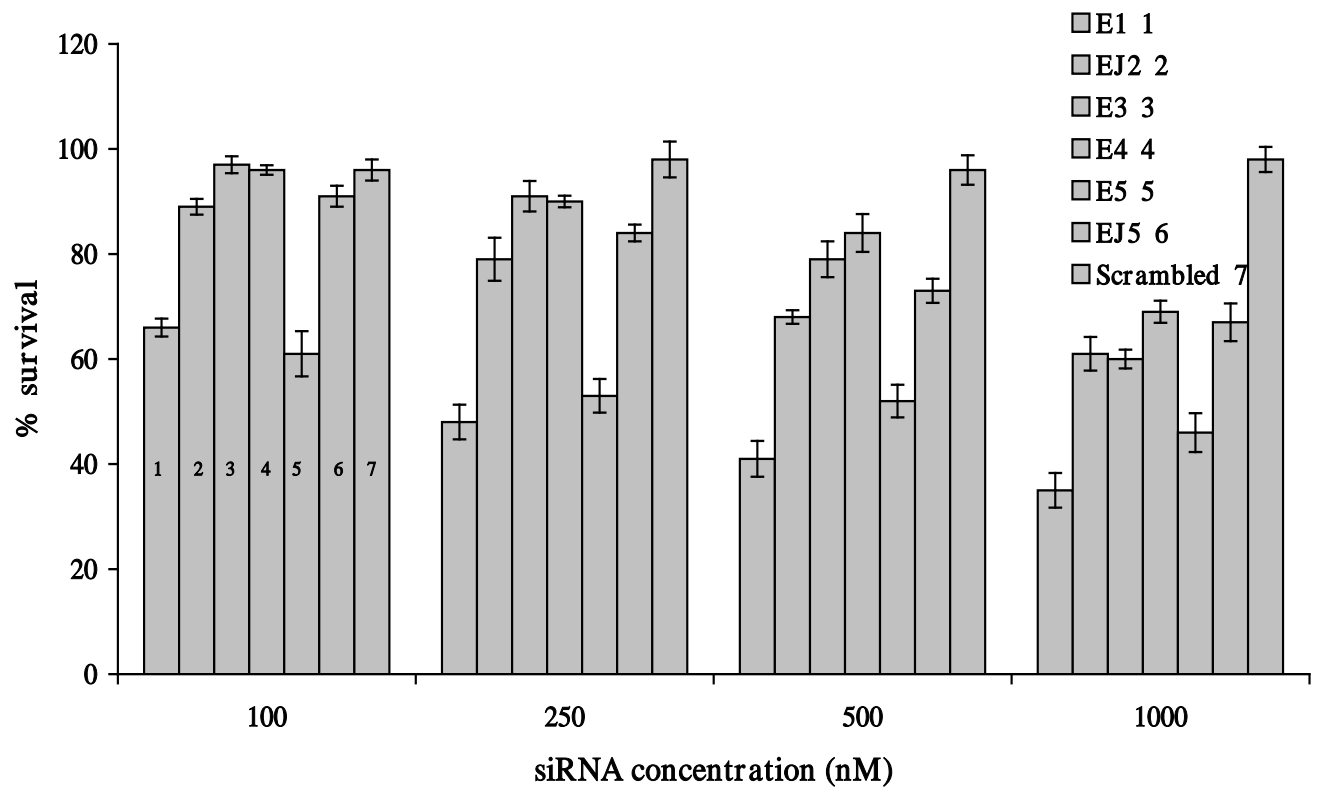

B

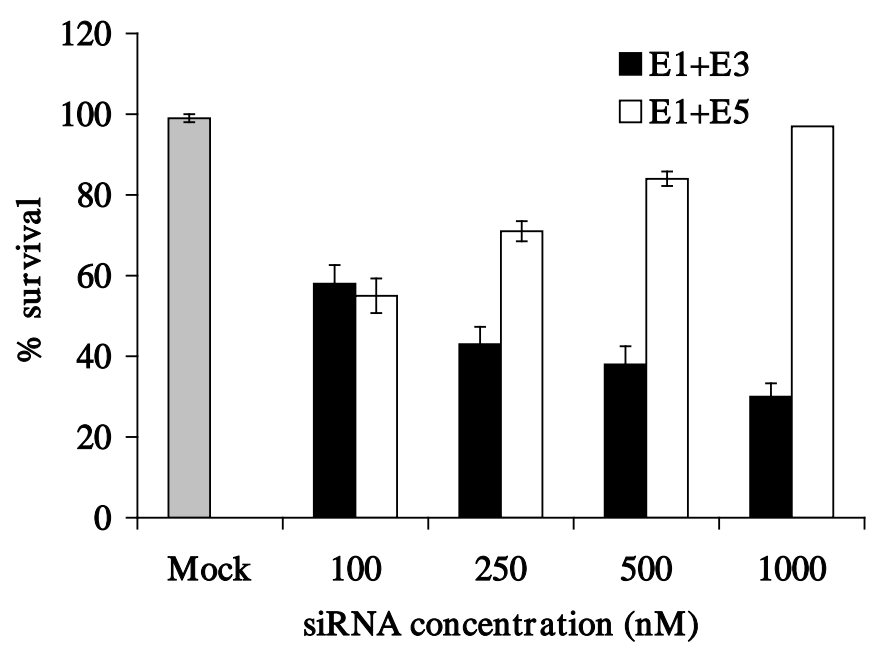

Fig. (3). Dose-dependent growth inhibitory effect of lipoplexes containing Bcl-2 and Bcl-xL siRNAs. MCF-7 cells were plated in $24-$ well plates $\left(7.5 \times 10^{4}\right.$ per well $)$ and transfected in triplicate with siRNA duplexes using siIMPORTER transfectant $24 \mathrm{~h}$ after plating and grown for an additional $48 \mathrm{~h}$. Growth-inhibitory effect of lipoplexes was compared to mock cells- cells treated with the tranfection reagent only, or cells transfected with scrambled siRNA. At the end of the transfection, cells were detached by trypsin and counted by hemocytometer using trypan blue to determine the number of viable cells. (A) E1, EJ2, E3, E4, E5, EJ5, Scrambled. (B) E1+E3 - black, E1+E5 - white, Mock - grey.

\subsection{Growth Inhibitory Activity of Various Lipoplexes Containing E1 siRNA}

E1 siRNA against Bcl-2 was the best Bcl-2 siRNA sequence. Therefore we checked the survival of MCF-7 cells transfected with E1 siRNA duplexes complexed with various cationic liposomes prepared by us. We found that lipoplexes containing E1 decrease the growth of MCF-7 cells in a timeand dose-dependent manner with a maximum inhibition at $72 \mathrm{~h}$ post transfection (Fig. 4). When MCF-7 cells were transfected with 25,50 or $100 \mathrm{nM}$ E1 siRNA complexed with DOTAP/DOPE UHV, the growth of MCF-7 cells was 60,31 or $11 \%$, respectively, as compared to controls (Student $t$ test, $p<0.05$, Fig. 4). In accord with the results in the previous section, growth inhibition was much smaller in MCF-7 cells treated with lipoplexes containing EJ2 siRNA than with E1 siRNA at identical concentrations. For instance, when MCF-7 cells were transfected with $100 \mathrm{nM} \mathrm{EJ} 2$ siRNA complexed with DOTAP/DOPE UHV, $81 \%$ of MCF-7 cells 


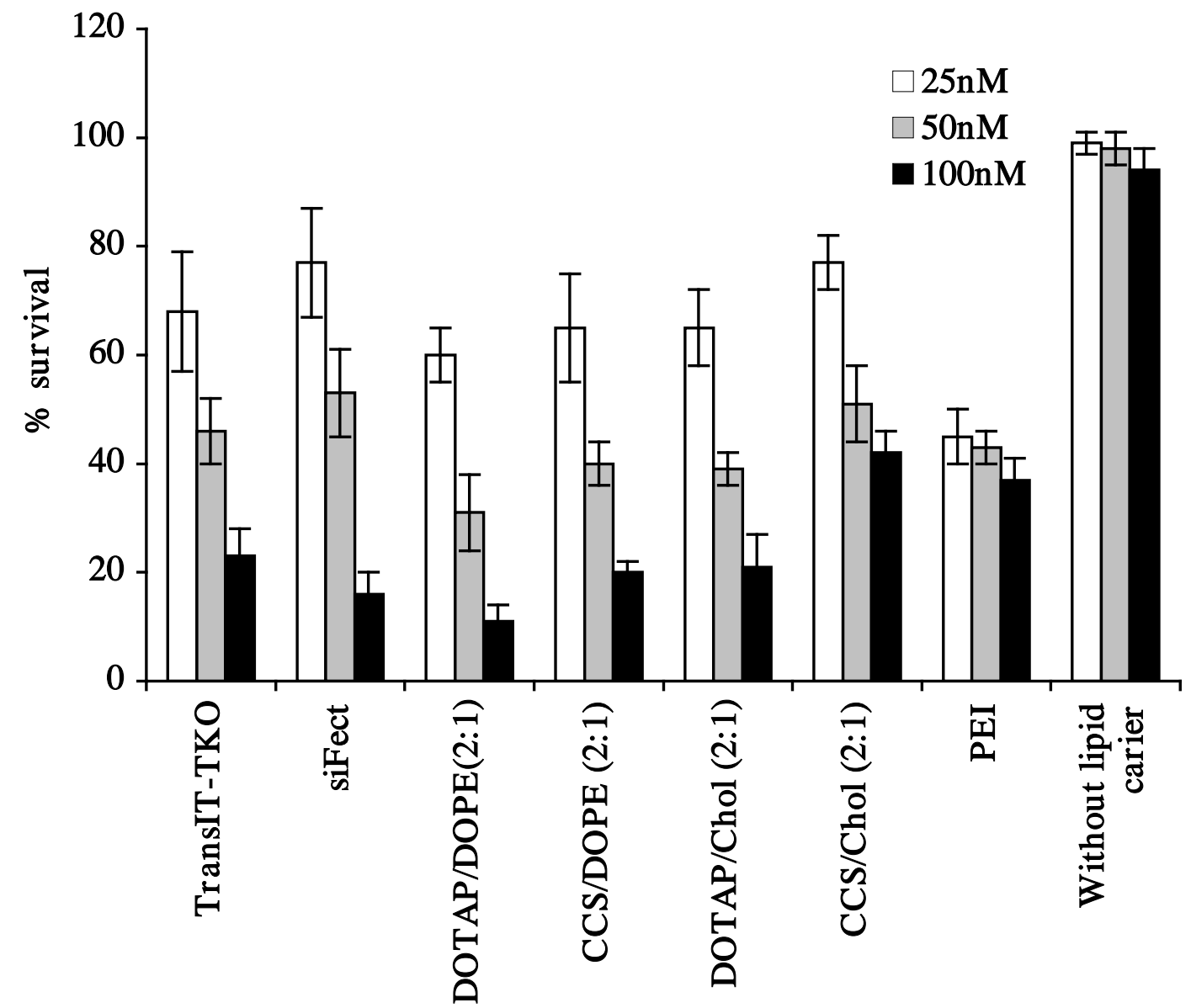

Fig. (4). Effect of lipoplexes having different lipid compositions on MCF-7 cell survival. For transfection experiments $4.0 \times 10^{3}$ cells were incubated with $25 \mathrm{nM}$ (white columns), $50 \mathrm{nM}$ (grey columns) and $100 \mathrm{nM}$ (black columns) E1 siRNA complexed with 2, 4 and 8 mM lipids, respectively, and grown for $72 \mathrm{~h}$. In the case of transfection with cationic polymer PEI, MCF-7 cells were treated with $25 \mathrm{nM}, 50 \mathrm{nM}$ and $100 \mathrm{nM}$ E1 siRNA complexed with $0.25,1$ and $2 \mathrm{mM}$ PEI, respectively. The commercially available carriers TransIT-TKO and siFect were compared to our lipid carriers. Cell survival was determined using methylene blue staining.

survived compared with only $11 \%$ when lipoplexes containing E1 siRNA were used. Regarding the other cationic lipoplexes, almost all showed comparable growth inhibition. 8095\% survival of cells treated with transfection reagent only (in all cases) was observed, indicating their low cytotoxicity (data not shown). In all cases, no growth inhibition was observed using naked duplexes (without lipid carrier). These studies confirm that siRNAs require an efficient carrier to achieve productive transfection.

We studied the effect of calcium(II) ions on siRNA-lipoplex-mediated transfection. We showed that $\mathrm{Ca}^{2+}$ ions also enhance the efficacy of siRNA lipoplexes, as addition of $\mathrm{CaCl}_{2}$ to siRNA lipoplexes further improved their growth inhibitory effect (Fig. 5).

\subsection{Comparing Bcl-2 3139 Antisense Oligonucleotide Lipoplexes with Bcl-2 E1 siRNA Lipoplexes}

Antisense Bcl-2 oligonucleotides such as G3139 were studied extensively [31]. Here we compared the ODN Bcl-2 lipoplexes previously optimized by us [43] with the Bcl-2 E1 siRNA lipoplexes used in this study. The growth inhibitory effect of E1 siRNA lipoplexes requires only $5 \%$ of the nucleic acid used to achieve similar inhibition by the Bcl-2 3139 ODN lipoplexes (Fig. 6). Others found that lower con- centrations of siRNA are needed to achieve levels of knockdown comparable to antisense reagents [44]. Moreover, in our previous work we have been able to knockdown Bcl-2 expression in MCF-7 cells with antisense DNA technology [40]. However, to achieve knockout of Bcl-2 with antisense, $50 \mu \mathrm{M}$ of DNA was required, while in the case of the siRNA, only 400-1000 $\mathrm{nM}$ concentration was required in order to achieve similar effect.

\subsection{Determination of Bcl-2 and Bcl-xL Expression in MCF-7 Cells Treated by the Appropriate siRNA}

In order to confirm that growth inhibitory effect was related to the level of $\mathrm{Bcl}-2$ or $\mathrm{Bcl}-\mathrm{xl}$ proteins, we evaluated the expression of these proteins by ELISA assay and Western blot analysis.

Fig. (7) depicts the results of ELISA assay of Bcl-2 expression in MCF-7 cells that were transfected with cationic lipid lipoplexes containing E1 siRNA for $16 \mathrm{~h}$. Suppression of Bcl-2 expression was observed only in cells transfected with lipoplexes containing siRNA, but not in cells transfected with cationic liposomes or with free siRNA. Addition of $\mathrm{CaCl}_{2}(25 \mathrm{mM})$ to the lipoplexes improved the efficacy and reduced further the level of Bcl-2 by $35-40 \%$. 


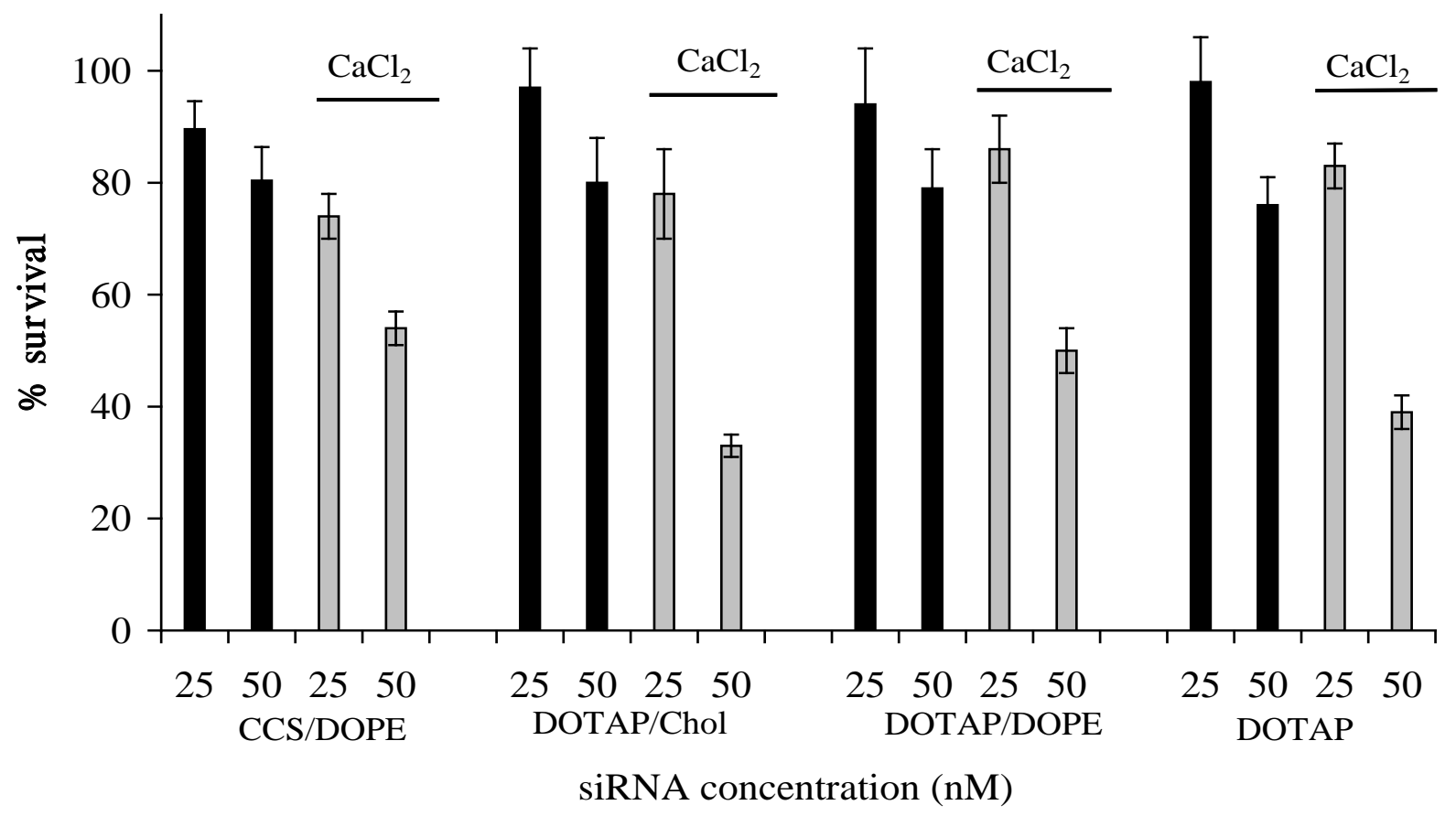

Fig. (5). Effect of $\mathbf{C a C l}_{2}$ as transfection enhancer of MCF-7 cell growth. Inhibition level of MCF-7 cell growth was quantified by methylene blue staining assay. Briefly, MCF-7 cells were plated in 96 -well plates $\left(4.0 \times 10^{3}\right.$ cells per well) and allowed to grow for $24 \mathrm{~h}$. Then cells were incubated at $37^{\circ} \mathrm{C}$ for $24 \mathrm{~h}$ with either 25 or $50 \mathrm{nM} \mathrm{E1}$ siRNA complexed with either 2.0 or $4.0 \mu \mathrm{M}$ lipids. $25 \mathrm{mM} \mathrm{CaCl}{ }_{2}$ was used. Error bars represent SD of two independent experiments.

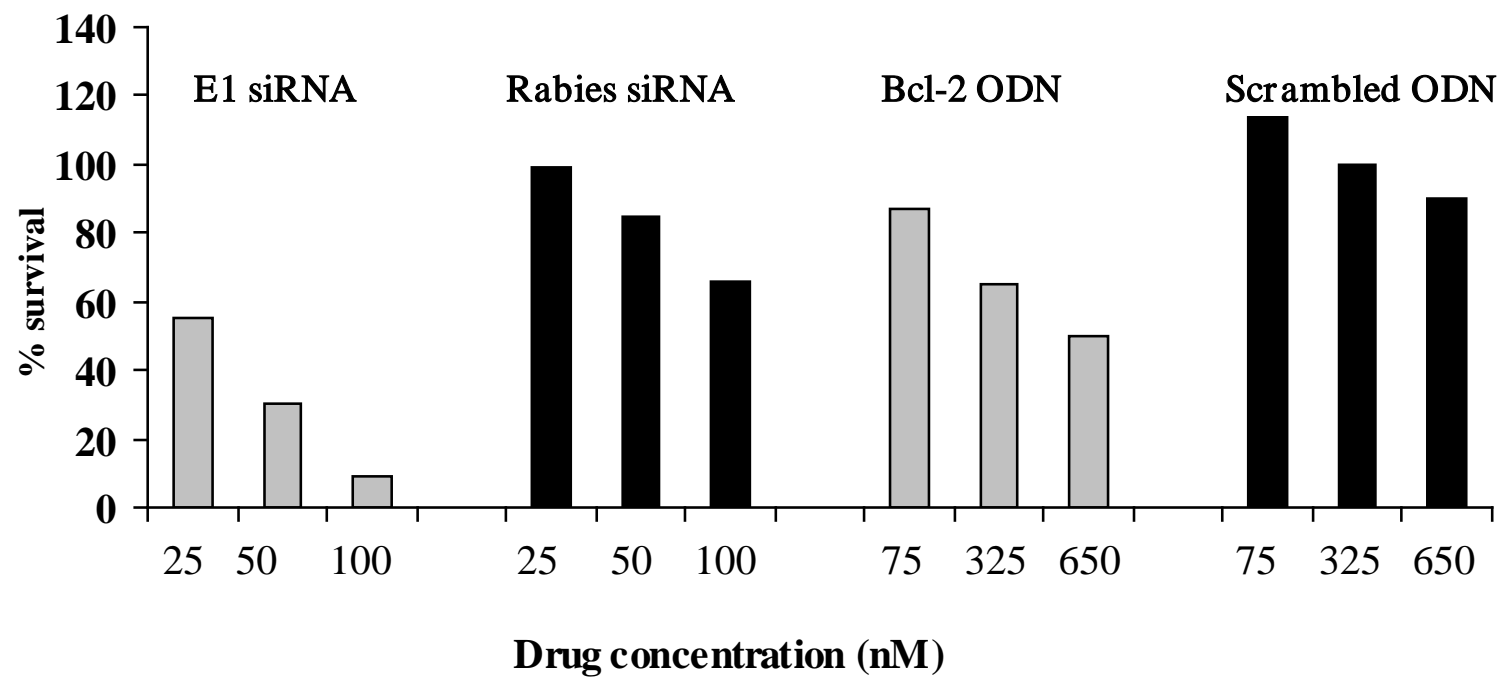

Fig. (6). Survival of MCF-7 cells treated with Bcl-2 E1siRNA or G 3139 Bcl-2 antisense ODN. Survival of MCF-7 cells treated with CCS/DOPE (2:1) lipoplexes containing Bcl-2 E1siRNA or G $3139 \mathrm{Bcl}-2$ antisense ODN for $72 \mathrm{~h}$ was evaluated by methylene blue staining assay. Controls included rabies siRNA and scrambled ODN.

In agreement with the ELISA assay, RT-PCR analysis (shown in Fig. 8C), indicated that Bcl-2 mRNA was dramatically reduced in cells treated with 400-1000 nM E1 Bcl2 siRNA. The effect was specific, as scrambled siRNA, like transfection agent, did not decrease Bcl-2 mRNA level. In addition, in cells treated with Bcl-xL E5 siRNA, a dramatic reduction of Bcl-xL mRNA was observed. As in the case with Bcl-2, the effect was specific. In addition, all three siRNA (Bcl-2, Bcl-xL and scrambled) did not decrease the level of the actin mRNA. Western blot analysis indicated that the protein level of $\mathrm{Bcl}-2$ and $\mathrm{Bcl}-\mathrm{xL}$ are significantly reduced as early as $24 \mathrm{~h}$ after siRNA lipoplex addition. The specificity of the siRNA effect can be demonstrated by the fact that Bcl-xL expression was not affected by siRNA directed towards $\mathrm{Bcl}-2$ and vice versa. None of these siRNAs affected levels of Bax, p53 or actin expression (Fig. 8A, B). The scrambled siRNA sequence did not cause any change in the tested protein levels as well. In summary, our results demonstrated that the growth inhibitory effect of Bcl-2 and Bcl-xL lipoplexes was caused by specific reduction in the level of these two proteins, each of them by its specific siRNA sequence. 


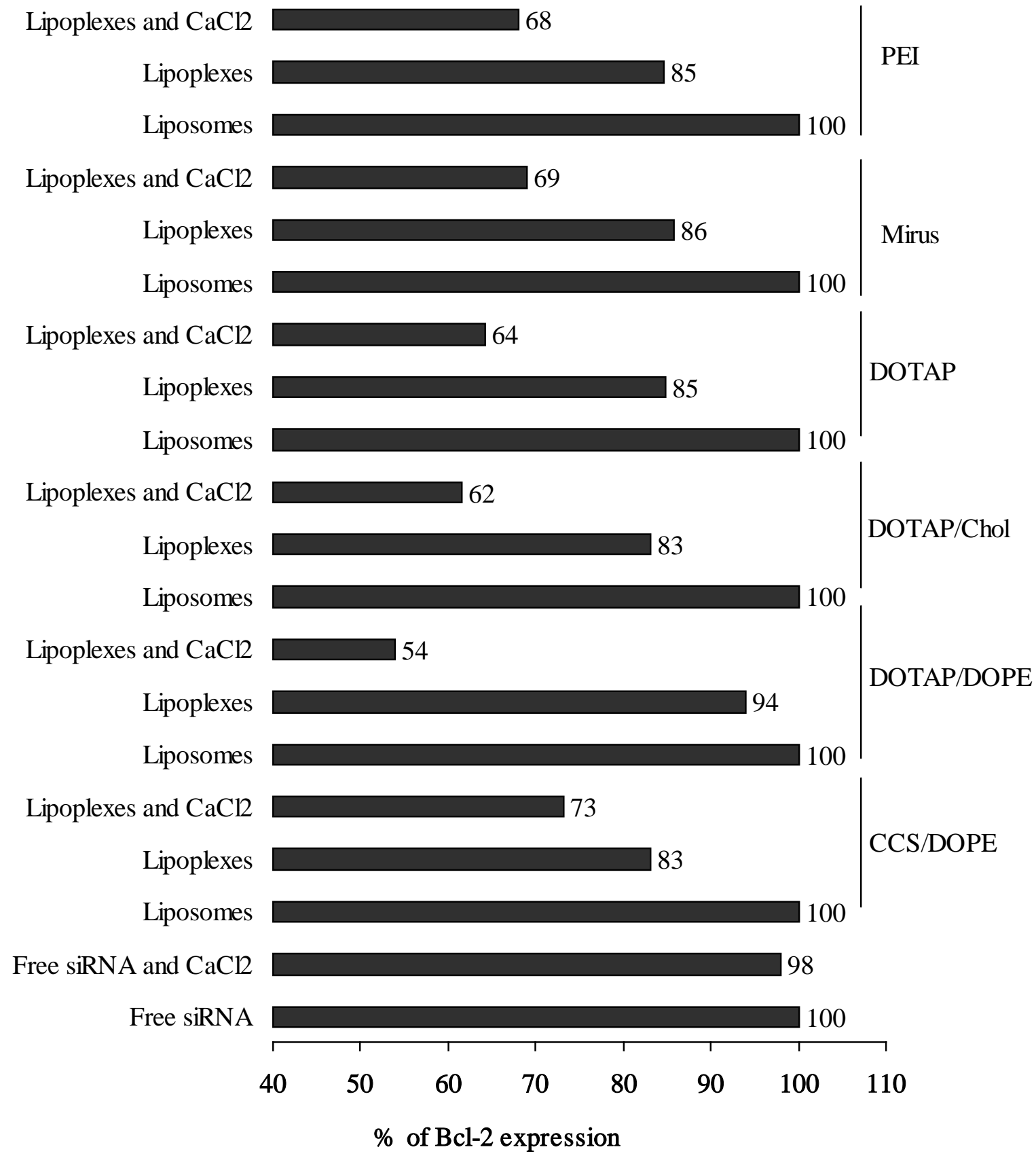

Fig. (7). Determination of the level of Bcl-2 protein expression in MCF-7 cells transfected with cationic lipid lipoplexes or liposomes. The level of Bcl-2 was determined in MCF-7 cells by Bcl-2 ELISA assay. Briefly, MCF-7 cells (10 ${ }^{6}$ cells/well) were treated for $16 \mathrm{~h}$ with 400 $\mathrm{nM}$ of various lipid/E1 siRNA formulations. Cell lysates were prepared and the level of Bcl-2 was checked in treated (lipoplexes) as compared to mock-transfected (liposomes) cells or cells transfected with free siRNA.

\subsection{Evaluation of Apoptosis}

To confirm that the growth inhibitory effect of Bcl-2 and Bcl-xL lipoplexes was due to induction of apoptosis by siRNA duplexes, MCF-7 cells transfected with E1, E5 or E1+E5 siRNA were compared to mock-transfected cells. The transfected cells were assessed $48 \mathrm{~h}$ later for level of caspase-7 activity and level of DNA fragmentation (both well-established markers for apoptosis). Fig. (9) shows induction of apoptosis in MCF-7 cells at $48 \mathrm{~h}$ post transfection by these three siRNAs as measured by caspase-7 activity (Fig. 9A) and DNA fragmentation (Fig. 9B).
Our results demonstrated that transfection of MCF-7 cells with E1 siRNA caused a significantly higher level of apoptosis determined by these two assays than with E5 siRNA (Wilcoxon $p<0.05$ ), in agreement with our growth inhibition results. This effect is specific, as the scrambled siRNA sequence did not induce apoptosis in transfected MCF-7 cells. The combination of E1+E5 siRNA sequences does augment apoptosis compared to each sequence alone at the same concentration; however, the effect is less than additive. In summary, growth inhibition correlates well with induction of apoptosis. 
A

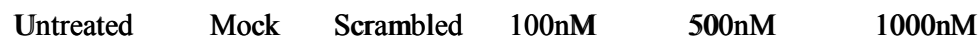

Bcl-2

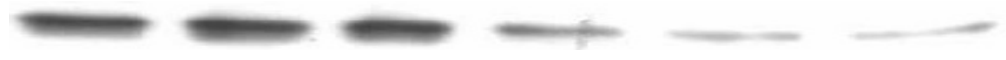

Bcl- $\mathrm{x}_{\mathrm{L}}$

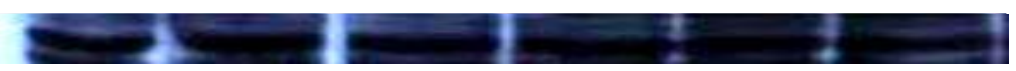

$\operatorname{Bax}$

p53

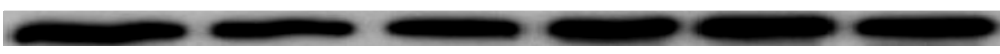

Actin

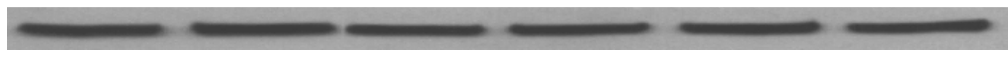

B

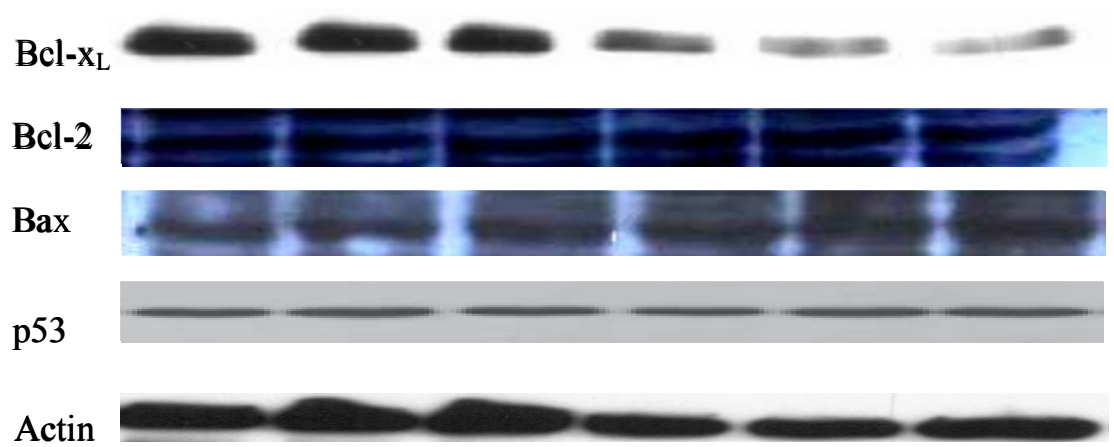

C

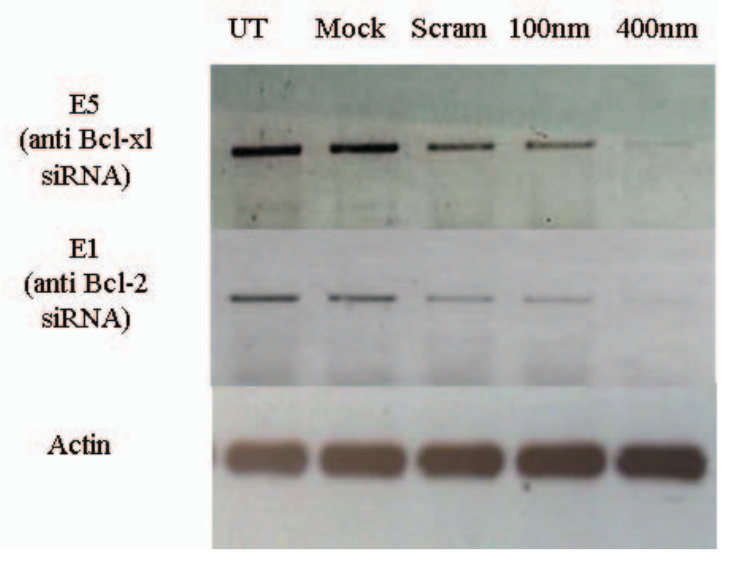

Fig. (8). Expression of Bcl-2, Bcl-xL, Bax, p53 and actin proteins in transfected MCF-7 cells by Western blot (A, B) or by RTPCR (C). MCF-7 cells (semiconfluent monolayer) were transfected with the indicated concentrations of E1 Bcl-2 (A) or E5 Bcl-xL siRNA (B) duplexes for $24 \mathrm{~h}$. Western blot analysis was carried out as described in Materials and Methods. (C) Cells were transfected with 100 or $400 \mathrm{nM}$ of either E1 siRNA (anti Bcl-2) or E5 (anti Bcl-xL), or with $400 \mathrm{nM}$ of scrambled siRNA (scram). Controls included cells treated with transfection agent only (mock) or untreated cells (UT). 24 hours after transfection cells were harvested and total RNA was extracted. RNA was subjected to RT-PCR with specific primers to ether Bcl-2, Bcl-xl or actin as indicated. The PCR products were run on $1 \%$ agarose gel.

\section{DISCUSSION}

\subsection{Physicochemical Characterization}

Transfection of cells by nucleic acids using lipoplexes as the delivery system requires complexation of the nucleic acids with cationic liposomes, followed by lipoplex uptake by the target cells. We therefore studied these two steps.

Our results of EtBr intercalation assay and of zeta potential measurement show good correlation, which indicates that lipoplexes composed of mono- or polycationic lipids with 
A

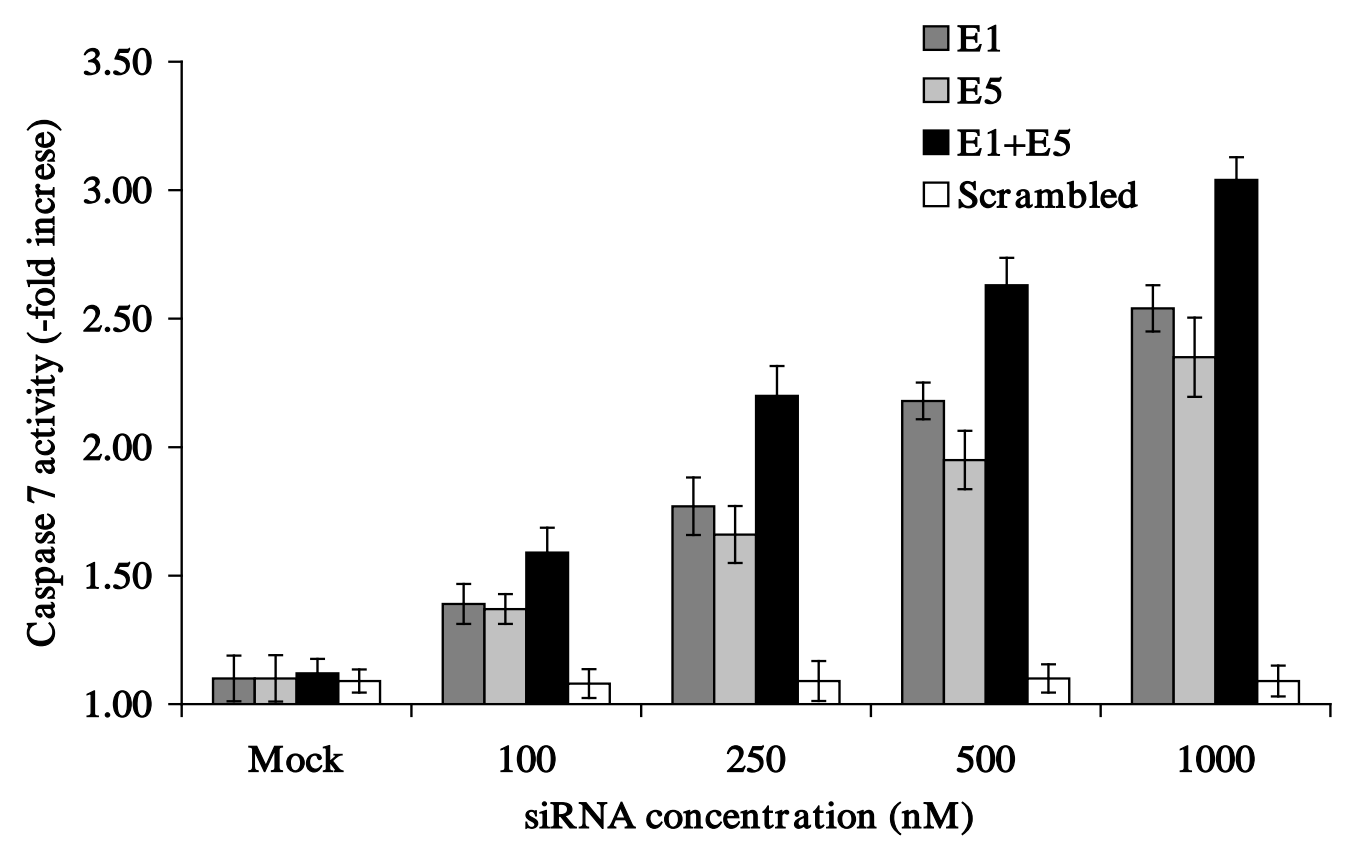

B

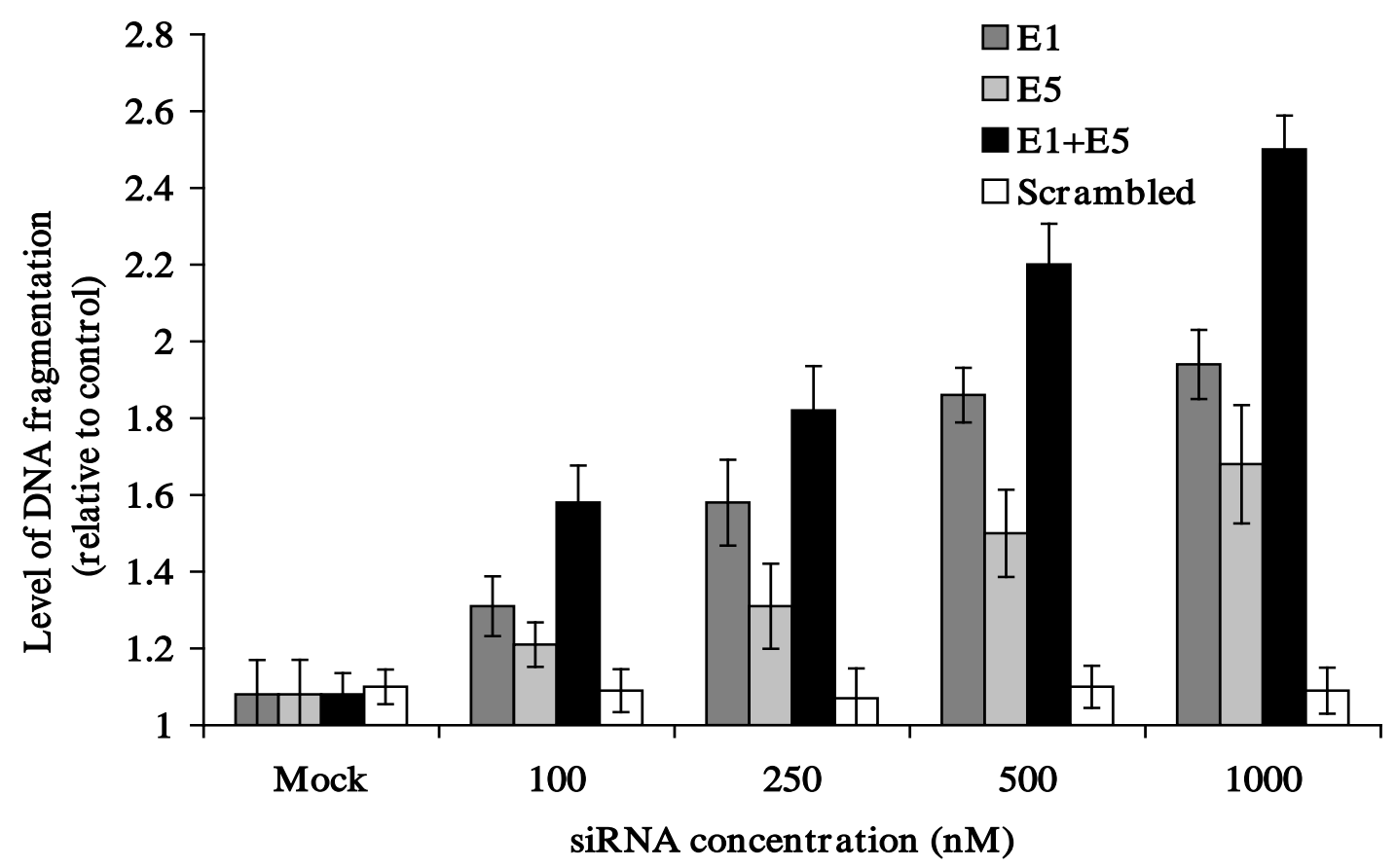

Fig. (9). Quantitation of apoptosis in MCF-7 cells transfected with various Bcl-2 siRNAs. MCF-7 cells were transfected by the indicated concentrations of siRNA duplexes. A - Caspase-7 activity was measured in MCF-7 cells at $48 \mathrm{~h}$ after transfection by Apo-ONE ${ }^{\text {tm }}$ Homoge- $^{-}$ nous Caspase-3/7 assay. B $-48 \mathrm{~h}$ after transfection cells were lysed and assayed for DNA fragmentation. E1 siRNA: dark grey, E5 siRNA: light grey, E1+E5 siRNAs: black, Scrambled siRNA: white.

Bcl-2 siRNA are formed. Efficiency of siRNA binding to cationic lipid UHV is high (80-100\%).

Size distribution measurements by DLS showed that addition of siRNA to either the monocationic DOTAP-based UHV or the polycationic CCS-based UHV resulted in their size increase (2-fold for the DOTAP systems and 10-fold for the CCS systems). These results are consistent with our previous results on cationic DOTAP/Chol-based liposomes complexed with ODN, showing that combining of ODN with cationic liposomes induces liposome aggregation and lamellar condensation [45]. That study showed that cationic 
membranes of the liposomes are adsorbed to each other by the ODN to form paired membranes. Close examination of cryogenic temperature transmission electron microscopy (cryo-TEM) images of paired membranes reveals that the plane of contact between bilayers has higher contrast than their outer edges, suggesting electron-dense ODN molecules sandwiched between the membranes (data not shown). This phenomenon can also explain liposome aggregation and size increase, as ODN molecules could "glue" adjacent liposomes together [45]. The much larger size increase in the CCS (compared to the DOTAP) system is related to the fact that CCS is polycationic while DOTAP is monocationic (see Scheme 1 with structural formulas).

\subsection{Transfection Efficiency}

Regarding cellular uptake of the lipoplexes, there were no significant differences between lipoplexes of various compositions, as $60-70 \%$ of MCF-7 cells took up either E1 or scrambled siRNA. Transfection efficiency of cells that express high levels of apoptosis-inhibiting Bcl-2 protein was quantified by determining if, and to what extent, the specific siRNAs reduce the level of $\mathrm{Bcl}-2$ and induce cell death. Overall, our results demonstrate that the effect of siRNA is specific, and that scrambled and mock siRNAs lack this effect. In addition, only siRNAs delivered via carrier lipoplexes or polyplexes were efficacious in promoting cell death and reducing Bcl-2 protein level. From the therapeutic point of view, it is very important that only 5\% E1 siRNA lipoplex is needed to exert the same cytotoxicity as Bcl-2 antisense oligonucleotide lipoplexes, which indicates higher efficacy and lower toxicity of siRNA lipoplexes. Comparing lipoplexes based on our own cationic lipid/siRNA (DOTAPor CCS-based) to commercial kits for siRNA delivery, we found that cytotoxic activity of our lipoplexes was comparable, and in some cases superior. Comparing the influence of size of DOTAP- and CCS-based lipoplexes, no significant differences were found in growth inhibition of MCF-7 cells. However, comparing our cationic lipid-based formulations, we found that DOTAP-based liposomes were less toxic than CCS-based liposomes and, more important, less toxic than commercial transfectants. Our results correlate with results of several other research groups. Sioud and Sorensen showed that cationic lipid complexes with siRNA can deliver siRNAs into various cell types [46].

The process of the lipoplex formation plays an important role in their transfection efficiency [22]. Particle size and surface charge of the lipoplexes are some of the important parameters affecting transfection efficiency [22]. We used $\mathrm{CaCl}_{2}$ as a transfection enhancer and found that, indeed, calcium(II) ions improve transfection efficiency as shown by the additional reduction of Bcl-2 protein level. According to our previous results with pDNA lipoplexes, addition of $\mathrm{CaCl}_{2}$ did not change particle size and zeta potential of the liposomes and lipoplexes (unpublished data). We proposed, in agreement with previous publications [24, 47] that calcium ions enhance DNA transfection by condensing DNA through neutralization of the phosphate groups of the DNA backbone.

The present study showed that siRNA directed towards Bcl-2 and Bcl-xL inhibited MCF-7 cell growth and induced apoptosis. Suppression of Bcl-2 expression was more effec- tive in growth inhibition, relative to suppression of Bcl-xL expression, despite achieving similar suppression of the respective gene product. This is consistent with the results of Leung and Wang, who found that, generally, estrogen-dependent breast cancer cells have higher Bcl-2 levels and lower Bcl-xL levels [48]. Therefore, cells expressing ER are appropriate targets, especially for $\mathrm{Bcl}-2$ gene silencing.

The efficiency of the various lipoplexes in suppression of the relevant gene product expression was variable: E1 and E5 were the most effective siRNAs towards Bcl-2 and Bcl$\mathrm{xL}$, respectively. The heterogeneity among different siRNA duplexes is well documented using multiple mRNA targets $[49,50]$. It is the result of several confounding factors, including the secondary conformation of the target mRNA and associated proteins, which may interfere with the access of the RISC complex to its target. The experiments in which two siRNAs were used simultaneously proved that this approach is feasible but not always advantageous. Therefore, the efficacy should be examined individually for each pair of siRNAs. We observed enhancement of gene silencing when Bcl-2 and Bcl-xL siRNAs were added together. This indicates that with the relatively low (less than $500 \mathrm{nM}$ ) concentrations employed, we have not yet reached saturation, and different siRNA duplexes were not competing for loading into RNA-induced silencing complex (RISC). The antagonistic effect observed in the combination of two Bcl-2 siRNAs may be the result of a spatial configuration that prevents the RISCs of E1 and E3 siRNAs to access the target area together. If we consider that the two target sequences are only 248 base pairs apart, we can understand how such a disturbance can occur.

The effect of siRNA, which culminated in the reduction of Bcl-2 and Bcl-xL, was specific to each protein, and there were no off-target effects. The unchanged levels of actin, p53 and Bax proteins are additional evidence for specificity. We found that reduction in the levels of Bcl-2 and Bcl-xL correlates with induction of apoptosis. The induction of apoptosis shows the promise of this technique, but it should be kept in mind that in vitro conditions differ greatly from in vivo.

\section{CONCLUSION}

Our studies show that siRNA delivered to tumor cells in the form of siRNA lipoplexes of various lipid compositions and in the form of PEI polyplexes resulted in specific growth inhibition of cancer cells in vitro. This was associated with reduction in the level of Bcl-2 and Bcl-xL proteins and with induction of apoptosis. We found that E1 siRNA lipoplexes were at least 20-fold more efficacious in growth inhibition than Bcl-2 antisense oligonucleotide. Moreover, selection of better (more efficacious and more stable) siRNA sequences than those used by us in this study, has the potential to improve further the silencing efficiency of siRNA. According to our results, Bcl-2 is a valid target for gene silencing in MCF-7 breast cancer cells. Based on experience with in vivo delivery of nucleic acids [22, 48], this study opens the road for efficient delivery of siRNA in vivo for treatment of various malignancies. Further investigation requires experiments to be done using optimized siRNA Bcl-2 and Bcl-xL sequences with additional cell lines and subsequently in animal models. Bcl-2 and Bcl-xL siRNA should also be combined 
with chemotherapeutic drugs (especially when loaded into liposomes) and apoptosis inducers such as ceramides [51] to explore the sensitization effects of gene silencing.

\section{ACKNOWLEDGEMENTS}

The partial support of the Israel Science Foundation and the Barenholz Fund to Y.B. and E.K. is acknowledged with pleasure. The help of Mr. S. Geller in editing this manuscript is greatly appreciated.

\section{ABBREVIATIONS}

\begin{tabular}{|c|c|c|}
\hline $\mathrm{BH}$ & $=$ & Bcl-2 homology \\
\hline Chol & $=$ & Cholesterol \\
\hline CCS & $=$ & $\begin{array}{l}\text { D-erythro- } N \text {-palmitoyl-sphingosyl- } \\
\text { carbamoyl spermine }\end{array}$ \\
\hline cryo-TEM & $=$ & $\begin{array}{l}\text { Cryogenic temperature transmission } \\
\text { electron microscopy }\end{array}$ \\
\hline DAPI & $=$ & 4,6-Diamino-2-phenylindole \\
\hline DLS & $=$ & Dynamic light-scattering \\
\hline DMEM & $=$ & Dulbecco's modified Eagle medium \\
\hline DOPE & $=$ & Dioleoylphosphatidyl ethanolamine \\
\hline DOTAP & $=$ & 1,2-Dioleyloxy-3-(trimethylamino)-propane \\
\hline dsRNA & $=$ & Double stranded RNA \\
\hline $\mathrm{EtBr}$ & $=$ & Ethidium bromide \\
\hline ER & $=$ & Estrogen receptor \\
\hline FAM & $=$ & 5'-Carboxy-fluorescein \\
\hline GSRT & $=$ & Gene silencing RNAi technology \\
\hline Hepes & $=$ & $\begin{array}{l}\text { N-(2-Hydroxyethyl)-piperazine-N'-2- } \\
\text { ethanesulfonic acid }\end{array}$ \\
\hline LUV & $=$ & Large unilamellar vesicles \\
\hline MB & $=$ & Methylene blue \\
\hline ODN & $=$ & Oligonucleotides \\
\hline PBS & $=$ & Phosphate buffered saline \\
\hline PEI & $=$ & Linear polyethyleneimine \\
\hline RISC & $=$ & RNA-induced silencing complex \\
\hline RT-PCR & $=$ & $\begin{array}{l}\text { Reverse transcription-polymerase chain } \\
\text { reaction }\end{array}$ \\
\hline siRNA & $=$ & Short interfering RNA \\
\hline UHV & $=$ & Unsized heterolamellar vesicles \\
\hline TNBS & $=$ & Trinitrobenzene sulfonic acid \\
\hline
\end{tabular}

\section{REFERENCES}

[1] Cory, S.; Adam, J.M. Nat. Rev. Cancer, 2002, 2, 647.

[2] Huang, Z. Oncogene, 2000, 19, 6627.

[3] Sorenson, C.M. Biochim. Biophys. Acta, 2004, 1644, 169.

[4] Thomadaki, H.; Talieri, M.; Scorilas, A. Cancer Lett., 2007, 247, 48.

[5] Thomadaki, H.; Scorilas, A.; Hindmarsh, J.T. Crit. Rev. Clin. Lab. Sci., 2006, 43, 1.

[6] Linjawi, A.; Kontogiannea, M.; Halwan, F.; Edwarde, M.; Meterissian, S. J. Am. Coll. Surg., 2003, 198, 83.
Silvestrini, R.; Benini, E.; Veneroni, S.; Daidone, M.G.; Tomasic, G.; Squicciarini, P.; Salvadori, B. J. Clin. Oncol., 1996, 14, 1604.

[8] Zhang, G.; Kimijina, I.; Abe, R.; Watanabe, T.; Kanno, M.; Hara K.; Tsuchiya, A. Anticancer Res., 1998, 18, 1989.

[9] Hellemans, P.; van Dam, P.A.; Weyler, J.; van Oosterom, A.T.; Buytaert, P.; Van Marck, E. Br. J. Cancer, 1995, 72, 354.

[10] Bonnefoy-Berard, N.; Aouacheria, A.; Verschelde, C.; Quemeneur, L.; Marcais, A.; Marvel, J. Biochim. Biophys. Acta, 2004, 1644, 159.

[11] Binimetskaya, L.; Lai, J.C.; Khvorova, A.; Wu, S.; Hua, E.; Miller, P.; Zhang, L.M.; Stein, C.A. Clin. Cancer Res., 2004, 10, 8371.

[12] Panaretakis, T.; Pokrovskaja, K.; Shoshan, M.C.; Grander, D. J. Biol. Chem., 2002, 277, 44317.

[13] Schon, M.P.; Schon, M. Apoptosis, 2004, 9, 291.

[14] Raffo, A.; Lai, J.C.; Stein, C.A.; Miller, P.; Scaringe, S.; Khvorova, A.; Benimetskaya, L. Clin. Cancer Res., 2004, 10, 3195.

[15] Lopes De Menesez, D.E.; Mayer, L.D. Cancer Chemother. Pharmacol., 2002, 49, 57.

[16] Zangemeister-Wittke, U.; Leech, S.H.; Olie, R.A. Clin. Cancer Res., 2000, 6, 2547.

[17] Jiang, Z.; Zheng, X.; Rich, K.M. J. Neurochem., 2003, 84, 273.

[18] Fu, G.F.; Lin, X.H.; Han, Q.W.; Fan, Y.R.; Xu, Y.F.; Guo, D.; Xu, G.X.; Hou, Y.Y. Cancer Biol. Ther., 2005, 4, 822.

[19] Lei, X.Y.; Zhong, M.; Feng, L.F.; Yan, C.Y.; Zhu, B.Y.; Tang, S.S.; Liao, D.F. Acta Biochim. Biophys. Sin., 2005, 37, 555.

[20] Lima, R.T.; Martins, L.M.; Guimaraes, J.E.; Sambade, C.; Vasconcelos, M.H. Cancer Gene Ther., 2004, 11, 309.

[21] Wacheck, V.; Losert, D.; Gunserg, P.; Vornlocher, H.P.; Hadwiger, P.; Geick, A.; Pehamberger, H.; Muller, M.; Jansen, B. Oligonucleotides, 2003, 13, 393.

[22] Simberg, D.; Weisman, S.; Talmon, Y.; Barenholz, Y. Crit. Rev. Ther. Drug Carrier Syst., 2004, 21, 257-317.

[23] Meidan, V.M.; Glezer, J.; Salomon, S.; Sidi, Y.; Barenholz, Y.; Cohen, J.S.; Lilling, G. J. Liposome Res., 2006, 16, 27.

[24] Bailey, A.L.; Sullivan, S.M. Biochim. Biophys. Acta, 2000, 1468, 239.

[25] Eliyahu, H.; Joseph, A.; Schillemans, J.P.; Azzam, T.; Domb, A.J.; Barenholz, Y. Biomaterials, 2007, 28, 2339.

[26] Spagnou, S.; Miller, A.D.; Keller, M. Biochemistry, 2004, 43, 13348.

[27] Hollins, A.; Fox, S.P.; Akhtar, S. Exogenous siRNA delivery: Protocols for optimizing delivery to cells, Boca Raton, FL: CRC Press, 2000.

[28] Felgner, P.L.; Barenholz, Y.; Behr, J.P.; Cheng, S.H.; Cullis, P.; Huang, L.; Jessee, J.A.; Seymour, L.; Szoka, F.; Thierry, A.R.; Wagner, E. Hum. Gene Ther., 1997, 20, 511.

[29] Jiang, M.; Milner, J. Genes Develop., 2003, 17, 832

[30] Eliyahu, H.; Joseph, A.; Azzam, T.; Barenholz, Y.; Domb, A.J. Biomaterials, 2006, 27, 1636.

[31] Meidan, V.M.; Glezer, J.; Salomon, S.; Sidi, Y.; Barenholz, Y.; Cohen, J.S.; Lilling, G. J. Liposome Res., 2006, 16, 27.

[32] Cioca, D.P.; Aoki, Y.; Kiyosawa, K. Cancer Gene Ther., 2003, 10, 125.

[33] Reynolds, A.; Leake, D.; Boese, Q.; Scaringe, S.; Marshall, W.S.; Khvorova, A. Nat. Biotech., 2004, 22, 326.

[34] Simberg, D.; Hirsch-Lerner, D.; Nissim, R.; Barenholz, Y. J. Liposome Res., 2000, 10, 1

[35] Barenholz, Y.; Gibbes, D.; Litman, B.J.; Goll, J.; Thompson, T.E.; Carlson, F.D. Biochemistry, 1977, 16, 2806.

[36] Simberg, D.; Weisman, S.; Talmon, Y.; Faerman, A.; Shoshani, T.; Barenholz, Y. J. Biol. Chem., 2003, 27, 39858.

[37] Garbuzenko, O.; Zalipsky, S.; Qazen, M.; Barenholz, Y. Langmuir, 2005, 21, 2560.

[38] Even-Chen, S.; Barenholz, Y. Biochim. Biophys. Acta, 2000, 1509, 176.

[39] Gorodetsky, R.; Levy-Acaba, F.; Mou, X.; Vexler, A.M. Int. J. Cancer, 1998, 75, 635.

[40] Lilling, G.; Hacohen, H.; Nordenberg, J.; Livnat, T.; Rotter, V.; Sid, Y. Cancer Lett., 2000, 161, 27.

[41] Onuki, R.; Kawasaki, H.; Baba, T.; Taira, K. Antisense Nucleic Acid Drug Dev., 2003, 13, 75 .

[42] Bradford, M.M. Ann. Biochem., 1976, 7, 248

[43] Meidan, V.M.; Cohen, J.S.; Amariglio, N.; Hirsch-Lerner, D.; Barenholz, Y. Biochim. Biophys. Acta, 2000, 1464, 251. 
[44] Nesterova, M.; Cho-Chung, Y.S. Curr. Drug Targets, 2004, 5, 683.

[45] Weisman, S.; Hirsch-Lerner, D.; Barenholz, Y.; Talmon, Y. Biophys. J., 2004, 87, 609.

[46] Sioud, M.; Sorensen, D.R. Methods Mol. Biol., 2004, 252, 515.

[47] Lam, A.M.; Cullis, P.R. Biochim. Biophys. Acta, 2000, 1463, 279.

[48] Leung, L.K.; Wang, T.T. Br. J. Cancer, 1999, 81, 387.
[49] Yoshinari, K.; Miyagishi, M.; Taira, K. Nucleic Acids Res., 2004, 32, 691 .

[50] Luo, K.Q.; Chang, D.C. Biochem. Biophys. Res. Commun., 2004, 318, 303 .

[51] Khazanov, E.; Priev, A.; Shillemans, J.P; Barenholz, Y. Langmuir, 2008, 24, 6965.

(c) Vestin et al.; Licensee Bentham Open.

This is an open access article licensed under the terms of the Creative Commons Attribution Non-Commercial License (http://creativecommons.org/licenses/by$\mathrm{nc} / 3.0 /$ )/ which permits unrestricted, non-commercial use, distribution and reproduction in any medium, provided the work is properly cited. 